\title{
Cross-linguistic variation in imperfectivity
}

\author{
Ana Arregui • María Luisa Rivero • \\ Andrés Salanova
}

Received: 11 February 2012 / Accepted: 30 August 2012 / Published online: 11 February 2014

(C) The Author(s) 2014. This article is published with open access at Springerlink.com

\begin{abstract}
The paper examines variation in the interpretations of imperfectives in Slavic, Romance, and Jê (Mẽbengokre). It develops a core modal analysis for an imperfective operator (IMPF) within situation semantics, coupled with languagespecific constraints formally encoded in modal bases. Cross-linguistic contrasts in the interpretation of imperfectives are explained in terms of variation in modal bases for IMPF, lexicalization patterns, and its interactions with other operators. The proposal accounts for why Romance languages use imperfectives to make reference to past plans while most Slavic languages do not, as well as for narrative uses specific to Romance languages, and factual uses specific to some Slavic languages. The proposal also accounts for lexically specified aspectual operators in Mẽbengokre, as well as language-specific interaction between IMPF and other modal operators, as in the Bulgarian Renarrated Mood, and two different semantic instances of Slavic Involuntary States. Appealing to cross-linguistic evidence to argue for a view according to which IMPF makes significant semantic contributions in all occurrences, the paper shows how a modal analysis can account for well-known temporal properties of imperfectives. It also demonstrates that data from closely related as well as unrelated languages provide evidence for an invariant semantic core behind imperfectivity.
\end{abstract}

Keywords Aspect · Imperfectives · Modality · Variation · Romance · Slavic . Mẽbengokre

\footnotetext{
A. Arregui ( $\varangle) \cdot$ M.L. Rivero · A. Salanova

University of Ottawa, Ottawa, ON, Canada

e-mail: aarregui@uottawa.ca

M.L. Rivero

e-mail: mrivero@uottawa.ca
}

A. Salanova

e-mail: kaitire@uottawa.ca 


\section{Introduction}

The goal of this paper is to seek an understanding of cross-linguistic variation in the semantics and morpho-syntax of imperfectivity from the perspective of a modal analysis.

While there is a large body of work on Imperfectives and their relation to modality, a general cross-linguistic picture is still missing. ${ }^{1}$ In the past, there has not been a systematic attempt to encompass the various interpretations available to Imperfectives in different languages within a unified view of the morphology, syntax, and semantics of imperfective aspect. ${ }^{2}$ In this paper, we argue that a cross-linguistic perspective is crucial to determine the contribution of imperfectivity, allowing us to identify what is intrinsic to the interpretation of Imperfectives. Both variation amongst closely related languages, i.e., micro-variation, and variation across language families, i.e., macro-variation, have a role to play in such a program. By including comparisons between Slavic, Romance, and Jê (Mẽbengokre), our paper takes a first step towards accomplishing such a program. We will see that, on the one hand, there is significant variation amongst closely related languages, showing that the same morpho-syntactic category varies in meaning within one family. Thus, it will not do to argue that what we consider variation in the interpretation of Imperfectives is simply a side-effect of mislabeling morpho-syntactic categories, and that under the umbrella term of 'imperfective' we are grouping together completely different phenomena. On the other hand, a comparison of imperfective-style morphology across unrelated languages is equally important, since it will allow us to see the various ways in which a family of meanings can be assembled in different morpho-syntactic architectures.

Languages may be very permissive regarding imperfective morphology, allowing for a wide range of meanings. Both Romance and Slavic, for instance, display a notoriously ambiguous imperfective morphology, embodying under one unique form readings known as 'ongoing', 'generic', etc. In spite of commonalities in numerous readings, we show that there is considerable variation in interpretations both when comparing Romance to Slavic, or languages within the Slavic family. In our view, the pervasive variation that arises from our comparison suggests that, even in the case of ambiguous imperfective morphology, there must nevertheless be formal restrictions in its semantics. That is, we take cross-linguistic variation in the readings in Romance and Slavic Imperfectives as indicative of constraints formally encoded in the syntax and semantics of an imperfective operator (henceforth, IMPF). This contrasts with views according to which variation in interpretations arises through purely pragmatic mechanisms based on general conversational principles, or as the result of languageinternal competition between marked and unmarked aspects.

Languages may also be very strict regarding the construction of aspectual meaning, tying a specific morpho-syntax to precise imperfective-like interpretations. In

\footnotetext{
${ }^{1}$ See, among others, Dowty (1979), Landman (1992), Portner (1998), Zucchi (1999), Cipria and Roberts (2000), Giorgi and Pianesi (2001, 2004), Copley (2002), Ippolito (2004), Rodríguez (2004), Hacquard (2006), Deo (2009), Cover (2011).

${ }^{2}$ Comparative studies, of course, exist. Samples include Dickey (2000) in Slavic, and Deo (2009), which describe cross-linguistic differences between imperfectives and progressives.
} 
this paper, we argue that Mẽbengokre belongs to the group with a highly specialized morphology for IMPF. Mẽbengokre aspectual markers share a morpho-syntactic architecture reminiscent of Romance and Slavic Imperfectives, but target specific flavors of imperfectivity at a lexical level.

In both types of languages, variation suggests that interpretations must be partly hardwired into the semantics/grammar of IMPF. Thus, we propose a shared semantic core for imperfective categories with language-specific constraints, and argue against accounts that consider imperfective aspect semantically vacuous, i.e., carrying no semantic information. The cross-linguistic perspective proves crucial in minimizing the role of pragmatics from two points of view. On the one hand, we argue that the view that shifts in the interpretation of Imperfectives arise from a type of coercion that relies on purely pragmatic procedures that are not grammatically encoded would have difficulties accounting for the various samples of cross-linguistic variation we identify in this paper. ${ }^{3}$ In this connection, our cross-linguistic perspective is useful to show that the richness of readings in imperfective sentences cannot simply be the result of pragmatic mechanisms triggered by semantic underspecification in the IMPF operator. On the other hand, we also argue that pragmatic approaches based on competition are unsuitable for some instances of variation identified in the paper. The logic of our approach, however, does not imply that pragmatic approaches should never be contemplated to account for nuances in the interpretation of IMPF.

We develop a modal analysis of IMPF within Kratzer-style situation semantics (Kratzer 2011), following Cipria and Roberts (2000). In their spirit, variation in the interpretation of Imperfectives is due to variation in the modal flavors available to IMPF, formally captured by means of constraints on the domain of quantification of a modal operator. In our proposal, cross-linguistic variation arises in various ways. There may be variation regarding the range of modal flavors available to IMPF: Romance languages, for example, allow Imperfectives to make reference to past plans, while most Slavic languages do not. There may also be variation in the degree of lexicalization for modal flavors: Romance and Slavic Imperfectives, for example, are highly ambiguous, while Mẽbengokre discriminates readings in the lexicon. In addition, there may also be variation that distinguishes one language from another due to the interaction between IMPF and other operators. In this paper we discuss two instances of such an interaction. In Bulgarian, IMPF interacts with an Epistemic Modal in the Renarrated Mood, which sets this language apart from many in the Slavic family and from Romance, while the invariant core in IMPF remains unaffected. In so-called Involuntary States in Slavic, IMPF with its invariant core interacts with a Circumstantial Modal in a way that divides the family into two semantic groups without equivalents in Romance.

\footnotetext{
${ }^{3}$ The view that Imperfectives are semantically unmarked is prominent in Slavic (for early references see, among others, Forsyth 1970 on Russian, and Altshuler 2010 for a recent survey). Some Romance traditions view Imperfectives as semantically marked, and Preterites/Aorists as semantically unmarked/undefined; in some recent proposals on French, however, IMPF lacks semantic information, so could be called unmarked, with its content derived from null operators in the clause (see, for instance, de Swart 1998 and Hacquard 2006 for different implementations of this idea). (Pure) pragmatic coercion has been suggested by Cipria and Roberts (2000) for Spanish Imperfectives we call 'Intentional' in Sect. 3.3, and by Smith (1991) and Labelle (2003) for French Narrative Imperfectives we discuss in Sect. 4.2.
} 
Our aim is to show that cross-linguistic variation can be understood in terms of slightly different crystallizations of a modal IMPF operator. Selecting some samples of data to illustrate variation, our overall goal is to provide a unified perspective on imperfectivity as a framework to understand similarities and differences between languages, not to provide detailed analyses for any specific language. The Romance and Slavic cases chosen as samples for discussion in this paper have been examined previously in a large and well-established literature, so we omit much background information. By contrast, Mẽbengokre is less known, so we present more background information on this language.

The structure of the paper is as follows. In Sect. 2, we present our modal proposal for IMPF. In Sect. 3, we begin by addressing interpretations shared across Romance and Slavic, namely generic/habitual and ongoing readings. We continue by identifying a first case of micro-variation we place under the 'Inertia' label. We show that Romance Imperfectives we dub 'Intentional' following Cipria and Roberts (2000) allow for readings that report past plans, but these are not available in all Slavic languages: some Slavic languages allow Intentional Imperfectives (Bulgarian) while most do not (Russian, Polish, etc.). We analyze this variation in terms of different modal bases associated with IMPF. We continue in Sect. 4 with two other cases of variation between Slavic and Romance: Factual Imperfectives, available in Russian and Polish but not Romance, and Narrative Imperfectives, available in Romance but not Russian and Polish. We consider these readings mirror images of more familiar inertia readings. In Sect. 5, we address a clear case of macro-variation, arguing that in Mẽbengokre, meanings associated with IMPF are encoded in distinct lexical items, which nevertheless share a syntactic architecture and core structural properties with imperfective categories in Romance and Slavic. Mẽbengokre thus illustrates variation due to a rich lexicalization strategy unavailable to IMPF in Romance or Slavic. We also show that IMPF aspectual operators in this language behave as syntactic heads that take nominalized complements in syntax, and can participate in two distinct structural configurations, allowing some to take subjects, while others do not. In Sect. 6, we turn to the interaction of IMPF, with its common core and various modal flavors, with other operators in the clause. The general aim of this section is to show that, even though IMPF has a unitary core, such interactions can be the source of further semantic variation, distinguishing Romance and Slavic languages from one another in important ways. This section also shows that Imperfectives make their own semantic contribution when interacting with other operators. Concluding remarks can be found in Sect. 7 .

\section{The general architecture for IMPF}

Our main goal is to identify and examine cross-linguistic commonalities and differences in imperfective readings within a unified framework, not to engage in comparisons of the numerous theoretical approaches to aspect. Our proposal for the interpretation of Imperfectives builds on previous modal analyses that associate imperfective morphology with a universal modal operator (IMPF), in particular Cipria and Roberts 
(2000). The different flavors associated with IMPF depend on the domain of quantification associated with the modal operator. In our proposal, restrictions on the domain capture variation in the interpretation across languages.

Cipria and Roberts' proposal is framed within a Kratzer-style situation semantics (Kratzer 2011, a.o.), allowing for a unified perspective on times and possible worlds. This is particularly well suited for the semantics of IMPF, which has both temporal and modal dimensions. In Sect. 2.1, we sketch the background behind the semantic details of our proposal. (Readers not interested in such details may prefer to skip this section.) In Sect. 2.2, we spell out the basic syntactic and semantic architecture for IMPF.

\subsection{Quantification over situations}

Following Kratzer (1989, 2002, 2011), we will spell out the semantics of IMPFs in a semantic framework that appeals to situations. According to Kratzer, situations are parts of possible worlds. Our semantic proposal will thus evaluate truth in parts of worlds, as well as in worlds themselves. Situations can be related by the 'part-of' relation $(\leq)$ : situations can have other situations as parts, and be themselves part of other situations. Worlds are maximal situations: situations that are not proper parts of other situations. Situations are not to be reduced to spatio-temporal locations within a world. (Indeed, there can be more than one situation in a single spatio-temporal region, and a single situation can include disconnected spatio-temporal parts. ${ }^{4}$ ) However, as parts of what is going on, they have both temporal and spatial coordinates within a world. This is what makes them particularly interesting to us: situations are at the same time temporal (i.e., they are part of some temporal slice within a world), and modal (i.e., they are part of some world and not others). Thus, situations provide an ideal vantage point from which to look for a unified semantics for IMPF, famous both for its temporal and modal properties.

We characterize IMPF as a quantifier over situations, following the tradition that treats this operator as a universal quantifier (Bonomi 1997; Cipria and Roberts 2000; Deo 2009; a.o.) (see footnote 8). There are various ways of identifying the domain of quantification of IMPF. Quantification can take place over situations that are part of the same world, situations in different worlds, and over worlds themselves. When it takes place over situations in the evaluation world, the quantification machinery delivers results that are extensional, mimicking non-modal quantification, with truth depending only on what is actually happening. For example, when quantification takes place over situations characterized as slices of the actual world, predictions are similar to those made with quantification over times (times are often construed as world-slices). So, even though the machinery for quantification is, in a sense, modal, the outcome in such cases will be extensional, with results depending only on what happens in the actual world. (Here the notion of extensionality corresponds to worldextensionality; see Landman 1989 and Cohen 1999 for discussion.)

\footnotetext{
${ }^{4}$ According to Kratzer, the part-structure is very fine-grained. Readers unfamiliar with the situations framework are referred to Kratzer (2011) for details.
} 
Given Kratzer's assumptions, situations are part of at most one world. However, in dealing with the modal flavors of imperfectivity, it will become necessary to identify situations across worlds in order to talk about possible (but not actual) continuations for actual events. For this, we adopt Lewis's account of the 'transworld identity' of individuals (Lewis 1968, 1986), and propose that situations are identified across worlds by means of counterpart relations. Consider the illustrations in (1). ${ }^{5}$



The situation $\mathrm{s}_{1}$ is part-of $\mathrm{w}_{1}\left(\mathrm{~s}_{1} \leq \mathrm{w}_{1}\right)$, but not of $\mathrm{w}_{2}$. However, if $\mathrm{s}_{2}$ is sufficiently similar to $s_{1}$ (given a contextually established similarity relation), it will count as its counterpart in $\mathrm{w}_{2} .{ }^{6}$ We can define a notion of 'modal-part-of' based on counterparts so that, even though $\mathrm{s}_{1}$ is not a part-of $(\leq) \mathrm{w}_{2}, \mathrm{~s}_{1}$ is a modal-part-of $(\leq$ modal $) \mathrm{w}_{2}$. The modal-part-of relation is defined in (2).

\section{Modal part-of:}

A situation $\mathrm{s}$ is a modal part of $\left(\leq_{\mathrm{m}}\right)$ a situation $\mathrm{s}^{\prime}$ iff there exists a situation $\mathrm{s}^{\prime \prime}$ such that $\mathrm{s}^{\prime \prime}$ is a counterpart of $\mathrm{s}$ and $\mathrm{s}^{\prime \prime} \leq \mathrm{s}^{\prime}$.

(Arregui 2010)

Given the notion of modal-part-of in (2), we can say that in (1) $s_{3}$ is a modal extension of $s_{1}$ (it has a counterpart of $s_{1}$ as a proper part $(\leq)$ ). We can also say that $s_{1}$ (modally) continues in $s_{3}$ : the beginning stages of $s_{3}$ are a counterpart of $s_{1}$, and $s_{3}$ extends (temporally) beyond that counterpart. The notions of 'modal extensions' and 'continuation' will be important in our semantics for IMPF in Sect. 3.3, where it will be necessary to talk about inertia situations (= 'continuations') for a topic situation.

As noted earlier, there is a special set of situations corresponding to possible worlds (maximal situations). We also distinguish another special set, corresponding to events. We follow Kratzer (2011) in characterizing events as situations that exemplify predicates: the events corresponding to the VP will be the situations that exemplify the VP-predicate. We make the informal assumption that a P-event is a situation that does not contain anything that does not contribute to the truth of $\mathrm{P}$ (Kratzer 2011, see text for explicit proposal and discussions).

Kratzer's framework delivers quantification over parts of worlds, which results in a very powerful machinery that can move seamlessly across categories traditionally kept apart, such as tense and aspect (times and events), and modality (worlds). This will be important when we later spell-out the semantics of IMPF, which can move across temporal and modal readings. With IMPF as a universal quantifier over situations, a single underlying semantics for IMPF can account for a range of readings on the basis of different ways of establishing domains of quantification. When IMPF quantifies over situations in the actual world, we obtain (typically) temporal/generic

\footnotetext{
${ }^{5}$ We use $s$ as a variable ranging over situations, $\leq$ for the part-of relation (reflexive), $w$ as a variable ranging over possible worlds, and $e$ as a variable ranging over events.

${ }^{6} \mathrm{We}$ omit discussion of counterpart theory here. For counterparts in philosophy, see Lewis (1968, 1986). For counterparts in a situation-based account of counterfactuals and deontics, see Arregui (2009, 2010).
} 
readings. When IMPF quantifies over situations in other worlds, we obtain modal readings.

\subsection{The core architecture and interpretation for IMPF}

We make standard assumptions regarding the syntactic projection of IMPF below Tense and above VP/vP. Following Kratzer (2011), among others, we assume that the evaluation of assertions is made in relation to a topic situation represented syntactically. The idea that sentences are evaluated in relation to topic situations has a long tradition, attributed originally to Austin (1950). We assume a referential approach to tense (see Partee 1973, a.o.), but couch the proposal within a situations framework, identifying tense with the topic situation (for detailed discussion, see Kratzer 2011, as well as the implementation in Arregui 2009). The summary of our syntactic assumptions is the hierarchical structure in (3) for Romance and Slavic.

$$
\left[\mathrm{TP} \text { Tense }_{\mathrm{i}}[\mathrm{AspP} \text { IMPF }[\mathrm{vP} \ldots \mathrm{V} \ldots . . .]]\right.
$$

For Mẽbengokre, a head-final language (see Sect. 5), we assume that aspect embeds a nominalized clause (Salanova 2007), as in (4). In all cases, the interpretation of IMPF follows the pattern in (5).

$$
\text { [TP } \text { Tense }_{i}\left[\text { AspP } \left[\text { Nominalization... } V_{\text {nom }} . .\right.\right. \text { ] IMPF]] }
$$

\section{Interpretation of IMPF}

Given a context $\mathrm{c}$ and variable assignment $\mathrm{g}$, $\llbracket \mathbf{I M P F} \rrbracket^{\mathrm{c}, \mathrm{g}}=\lambda \mathrm{P}_{<\mathrm{l},<\mathrm{s}, \mathrm{t}>>} \cdot \lambda \mathrm{s} . \forall \mathrm{s}^{\prime}: \mathrm{MB}_{\alpha}(\mathrm{s})\left(\mathrm{s}^{\prime}\right)=1, \exists \mathrm{e}: \mathrm{P}(\mathrm{e})\left(\mathrm{s}^{\prime}\right)=1$, defined only if there is a contextually or linguistically determined salient modal base (MB) of type $\alpha$.

First, let us clarify some aspects of the modal semantics we propose in (5). In (5), 1 is the type for events, $\mathrm{s}$ is the type of situations, $P$ is a variable ranging over properties of events, and $\mathrm{MB}_{\alpha}$ is a contextually or linguistically determined 'modal base'. We use the term modal base (abbreviated MB) here even though we are technically appealing to an accessibility relation: a function from situations to sets of situations: $<\mathrm{s},<\mathrm{s}, \mathrm{t}>>$. As discussed by Kratzer (1991), among others, it is possible to identify an accessibility relation in terms of a modal base, so the switch in terminology should not prove problematic. The term 'modal base' is familiar in the linguistic literature dealing with flexibility in the interpretation of modals, and we consider it helpful in this context. It should, however, be noted that we are not, technically speaking, appealing to Kratzer-style modal bases, but rather to accessibility relations.

According to (5), IMPF combines with a property of events $\mathrm{P}$, and results in a property of situations true of a situation $s$ iff in all situations $s^{\prime}$ accessible to $s$ given a modal base, there exists a P-event (i.e., $\mathrm{s}^{\prime}$ has as part a situation exemplifying P). In the forthcoming text, we at times simplify this to $\exists \mathrm{e}$ : e is an event of $\mathrm{P}$ in $\mathrm{s}^{\prime}$. As noted earlier, the proposal falls within a long tradition that has characterized the imperfective as a universal modal quantifier (including Cipria and Roberts 2000). ${ }^{7}$

\footnotetext{
${ }^{7}$ Our focus in this paper is on the modal flavors associated with Imperfectives, and we will not be able to address in detail alternative proposals on quantificational strength, a topic we leave for future research.
} 
Within the aspectual literature, imperfective viewpoint aspect has traditionally been characterized as an operator that locates the reference time or topic time within the event time. (We dub such an approach a 'temporal-inclusion view'; see Klein 1994; Smith 1997; Kratzer 1998; among many others.) The proposal in (5) differs from this type of approach in not establishing a direct relationship between the topic situation (similarly to the reference/topic time) and the time of the event (see also Cipria and Roberts 2000; Ippolito 2004; a.o.). Indeed, according to (5), the event corresponding to the VP-predicate must be completely included within the situations quantified over. We will show that the temporal-inclusion view fails to characterize readings we place under the common umbrella in (5) (including Intentionals, Factuals, and Narratives), and is thus too narrow to cover the range of readings of Imperfectives. In Sect. 3 and Sect. 4, we discuss how the modal semantics in (5) accounts for the full range of readings, and also how it makes correct predictions for cases in which temporal inclusion is required, thus also capturing relevant temporal relations.

Our implementation of (5) differs from other modal accounts of Imperfectives in allowing the choice of MB to be specified on a language-dependent basis. Contrary to Cipria and Roberts' account for Spanish, we argue that the MBs that may be invoked by IMPF are not purely context-dependent, but that the range of options is hardwired into the semantics in each language. (This can be encoded as a presupposition attached to IMPF that $\alpha$ is of type a or b or c, etc., depending on the language.)

As we will see in the following sections, each of the MBs associated with IMPF requires quantification over situations that match the topic situation with respect to certain facts. Adopting Kratzer's terminology, we could say that the flavors of IMPF are all instances of circumstantial modality (i.e., modality that cares about facts in the evaluation world, independently of the knowledge or beliefs of an agent or speaker). Given the data discussed in this paper, MBs associated with IMPF differ from MBs standardly associated with ordinary modals in the literature in so far as in the case of IMPF the focus of MBs is on the distribution of events with respect to the topic situation: IMPF is interested in the (normal) distribution of events within a topic situation, or in events in the normal continuation or result state of the topic situation, or events that are started or prepared in the topic situation. Thus the modality related to IMPF is very much event-centered. In each interpretation, we can recover a basic question: Do certain facts (the topic situation) support (i.e., make true) a certain event property (the VP predicate) in normal circumstances (where the restriction to "normal circumstances' could just be a default setting in identifying a modal domain of quantification)? This is different from other more familiar types of modality, where facts are obviously relevant, but truth depends also on beliefs/knowledge, content, goals, laws, etc. It is tempting to speculate that the syntactic position of Viewpoint aspect with VP as its c-command domain, which contrasts with modal operators in

We will show in later sections that the universal approach makes correct predictions for the data discussed in this paper (see also Deo 2009 for a solution to problems noted for a universal analysis of IMPF by e.g. Bonomi 1997). There has, however, been debate in the literature regarding the quantificational force of Imperfectives, in particular in relation to generic readings. Cohen (1999) has argued for a probabilistic interpretation of generic sentences, which often include Imperfectives, and Menéndez-Benito (2005), for example, has argued that in dispositional readings, Imperfectives are interpreted as existential modal quantifiers. 
higher domains, plays a role in determining a rather minimal, event-centered modality, reminiscent of views in the literature locating circumstantial modality relatively low within the functional space of syntactic trees. We do not have a fully articulated theory that is able to tie the interpretation of modality to positions within the functional domain of a syntactic structure, so our remarks remain speculative. Given our research so far, however, we do expect the modal flavors of IMPF in the syntactic structures in (3) and (4) to care about whether facts normally support event predicates as encoded in VP, and how such events are distributed with respect to the topic situation.

Our proposal to 'hardwire' options regarding MBs falls in line with recent research on language-specific restrictions on the choice of MBs. Rullmann et al. (2008) argue that in ordinary modals, MBs may be lexically encoded, and we propose to extend similar lexical restrictions to the realm of aspect. We see in Sect. 5 that Mẽbengokre provides an extreme example of lexicalization, with rich lexical specification in a distinct morphology for different readings. With the general architecture of IMPF in (5) in mind, in Sect. 3 we first illustrate and analyze some readings shared by Romance and Slavic (Sects. 3.1 and 3.2), before we turn to less general readings in Sect. 3.3, and embark on our quest to capture variation.

\section{Imperfectives in Romance and Slavic}

This section begins our comparison of Romance and Slavic, to be continued in Sect. 4. Looking first at commonalities, the two families share interpretations traditionally considered typical for Imperfectives, which we discuss briefly. Those include generic/habitual readings in Sect. 3.1, and ongoing readings in Sect. 3.2. ${ }^{8}$ In Sect. 3.3, we show that the range of interpretations of Romance and Slavic Imperfectives also varies, and note that while both families share uses that fall under the event-in-progress/incomplete-event labels, some Slavic languages display what we dub Intentional Imperfectives while others do not. ${ }^{9}$

\footnotetext{
${ }^{8}$ Languages may also vary as to the range of interpretations for Imperfectives considered prototypical in some grammatical traditions. For instance, according to Bhatt (1999a, 1999b, 2006), the reading for events in progress is absent with Hindi Imperfectives, which are specialized for a generic reading; Hindi ongoing readings are reserved for a progressive marker, so the imperfective marker is sometimes dubbed a habitual. We omit discussion of Slavic secondary imperfectives, but there are reports in the literature that in the present tense they display generic readings, and lack ongoing readings in several languages of the family; this restriction may not apply to Bulgarian, so the topic is in need of study. An anonymous reviewer points out that Portuguese simple Presents differ from Imperfects in lacking ongoing readings, which are reserved for periphrastic progressive Presents. Spanish also has periphrastic progressives, but seems to escape the Portuguese restriction mentioned by this reviewer; i.e., simple Presents share an ongoing reading both with Imperfects and with periphrastic progressive Presents.

${ }^{9}$ The instances of variation discussed in this paper do not represent an exhaustive list. We omit discussion of conditional constructions, which display considerable variation in both Romance and Slavic. On the one hand, Italian (see Ippolito 2004 for discussion), Rumanian, and Spanish in Romance allow past- and future-oriented Imperfectives in both antecedent and consequent clauses in conditionals; this is not the case in French (Anand and Hacquard 2009), where Imperfectives are excluded in future-oriented consequents. In Slavic, on the other hand, Bulgarian Imperfects are also possible in antecedent and consequent clauses in conditional constructions, thus resembling Rumanian and Spanish, whereas many Slavic languages require
} 


\subsection{Generic/habitual readings}

In our language sample, generic/habitual readings are general (we will not distinguish amongst them). They are found in Romance under a morphology that subsumes both imperfective aspect and past tense, and in Slavic, where past tense does not subsume imperfective aspect. We illustrate Romance generics/habituals in bold in (6a)-(6b) via Spanish (Sp) and Portuguese (Por). Slavic generics/habituals are in (6c)-(6e); Bulgarian (Bg) stands for South Slavic, Polish (Po) for West Slavic, and Russian $(\mathrm{Ru})$ for East Slavic. Similar examples could be given in other Romance and Slavic languages. ${ }^{10}$ Note that Impf is used as an abbreviation for Imperfective in (6a)-(6e) and throughout the examples in this paper.

(6) a. Hace veinte años, los niños veían menos televisión.

Make twenty years, the children saw.Impf less TV

b. Há vinte anos, as crianças viam menos televisão.

Por

Is twenty years, the children saw.Impf less TV

c. Predi 20 godini, decata gledaxa po-malko TV. Ago 20 years, children.the saw.Impf less TV

d. Dwadzieścia lat temu, dzieci spędzały mniej czasu przed telewizorem. Po Twenty years ago, children spent.Impf less time in.front.of TV

e. Dvadcat' let nazad, deti smotreli televizor men'she.

$\mathrm{Ru}$

Twenty years ago, children watched.Impf TV less

'Twenty years ago children watched (Impf) less TV.'

The crucial point for the proposals in this paper is that all the above patterns contain the IMPF operator depicted in the syntactic skeleton in (3), which shares the interpretation in (5). However, the languages selected for illustration in paradigm (6) differ as to the morphological means to achieve imperfectivity. Before we turn to our analysis of generics/habituals, it thus seems useful to offer some oversimplified remarks on the morpho-syntactic encoding of imperfectivity in our examples for readers unfamiliar with the Romance and Slavic systems.

The Romance sentences in (6a)-(6b) display verbs that agree in person and number with the subject, and those verbs are inflected in the Imperfect tense of the Indicative Mood. In Romance, the Imperfect tense is traditionally considered imperfective,

conditional auxiliaries. We also omit discussion of Romance ludic readings for future role-playing as in (i), and polite readings, as in (ii).

There are no (Past) Imperfective ludics for future roles in at least Bulgarian, but they could exist elsewhere in Slavic. Politeness is not often mentioned for Slavic (past) Imperfectives, but Forsyth (1970: Chap. 7.4.1) notes the 'over'-use of Russian Imperfective imperatives as attenuated commands.

${ }^{10}$ Morpheme-by-morpheme glosses are much simplified, and intended to capture just the relevant morphology. 
standing in opposition to perfective past tenses, which, depending on the language, may be the Aorist/Simple Past/Preterite, and/or the Perfect. The Polish and Russian sentences in (6d)-(6e) are representative of a morpho-syntactic situation that partially covers East and West Slavic languages. Examples (6d)-(6e) display morphologically imperfective verbs in contrast with (usually prefixed) perfective verbs, which in these patterns are inflected for a general past that takes the morphological shape of a participle that agrees in gender and number with the subject. South Slavic languages depart from West and East Slavic languages in a variety of ways, and Bulgarian in particular differs in so far as it combines Romance and Slavic characteristics. In sentence (6c), gledaxa, for instance, is both (i) an imperfective verb in contrast with a (usually prefixed) perfective verb, the Slavic-like dimension, and (ii) a verb inflected in the Imperfect tense of the Indicative Mood, thus in contrast with Aorist and Perfect, the 'Romance'-like dimension. Semantically, however, Bulgarian verbs inflected for the Imperfect tense are always imperfectives. Another way to express the situation in Bulgarian is that the Imperfect tense takes scope over the perfective morphology that may be found on the verb (for more details, see Scatton 1983 on the tense system of Bulgarian, and Rivero 2009 on the various morphological manifestations of IMPF in this language).

Now let us turn to our proposals for the paradigm in (6), and similar cases. Building on Cipria and Roberts (2000), we characterize generic/habitual Imperfectives in terms of quantification over characteristic situations. ${ }^{11}$ According to Cipria and Roberts, characteristic situations are those that are normal or usual, where both context and the utterance itself have a role in deciding what it is (see Cipria and Roberts 2000:325). Natural laws often play a role in identifying characteristic situations, resulting in quantification over situations that obey the laws of the evaluation world. In the case of generic/habitual sentences, quantification then takes place over characteristic sub-situations of the topic situation. ${ }^{12}$ In these cases, IMPF accesses the MB in (7).

(7) $\quad \mathrm{MB}_{\text {generic }}=\lambda \mathrm{s} \cdot \lambda \mathrm{s}^{\prime} . \mathrm{s}^{\prime}$ is a characteristic part of $\mathrm{s}$.

Given a topic situation provided by what was going on twenty years ago, truth conditions for (6) will be as in (8). (We do not analyze the comparative; for simplicity, we understand that the claim is that children watched less TV than now on evenings they watched TV.)

$$
\begin{aligned}
& \llbracket(6) \rrbracket^{c, g}=1 \text { iff } \\
& \forall s^{\prime}: M B_{\text {generic }}\left(s_{\text {relevant }} 20 \text {-years-ago situation }\right)\left(s^{\prime}\right)=1, \\
& \exists e: \text { e is an event of the children watching less TV than now in } s^{\prime} .
\end{aligned}
$$

According to (8), (6a)-(6e) will be true iff all relevant characteristic sub-situations of the topic situation are such that in them there was an event of children watching

\footnotetext{
${ }^{11}$ We will not address so-called dispositional readings here.

${ }^{12}$ The claim that Imperfectives lead to non-accidental generalizations even in the presence of overt adverbs of quantification has been made, for example, by Lenci and Bertinetto (2000) for Italian, and MenéndezBenito (2002) for Spanish.
} 
less than a certain amount of TV. Note that by analyzing the domain of quantification in terms of normal or expected situations, we surreptitiously introduce modality: we quantify over situations that obey the laws/expectations regarding TV watching by children then (e.g., children watch at most 2 hours of TV per day). Quantification is thus restricted to actual situations, but we make predictions regarding non-actual possible situations: if they are normal situations of children watching TV twenty years ago, they will also be situations of children watching an amount of TV that is smaller than what children watch now. The introduction of modality into the characterization of the domain of quantification (i.e., characteristic/normal situations) provides a way of understanding why Imperfectives are often used to make non-accidental generalizations.

Following remarks by Cipria and Roberts, we claim that the granularity of the domain of quantification is affected by the type of eventuality corresponding to the clause embedded under IMPF. The domain of quantification will consist of characteristic sub-situations that are large enough to accommodate an eventuality of the relevant kind. (One could think of this as a kind of presupposition projection from the nuclear scope to the restrictor, in the spirit of discussions in Heim 1982.)

In sum, Romance and Slavic generic/habitual Imperfectives share (5), and access MB (7). We see in Sect. 5 that Mẽbengokre also forms generic sentences via an operator above VP, thus semantic conditions in generics/habituals seem void of variation, even though morpho-syntactic conditions do vary across languages.

\subsection{Ongoing readings}

We use the label 'ongoing' for interpretations in which eventualities are claimed to keep happening within the topic situation (also known as 'processual' and 'repetitive'). Depending on the granularity of the eventuality, this will be the case either when a state or activity is (was) developing, or when there is iteration of telic eventualities. What is typical of ongoing interpretations is a homogeneous distribution of eventualities across the topic situation. (Traditionally, predicates are said to be homogeneous/atelic when they have the subinterval property. ${ }^{13}$ ) All languages in our sample permit ongoing interpretations for IMPF, as in (9).

(9) a. Cuando mi madre entró en mi habitación, yo hablaba con mi

When my mother came in my room, I talked.Impf with my novio.

boyfriend

b. Quando a minha mãe entrou no meu quarto, eu falava com o When the mother my entered in.the my room, I talked.Impf with the meu namorado.

Por

my boyfriend

\footnotetext{
${ }^{13}$ See Cipria and Roberts (2000) for a formal discussion. Informally, a property of situations $\phi$ is homogeneous iff for all situations s such that $\phi$ is true in s, it will also be the case that $\phi$ is true in all sub-situations of s. (The granularity of the predicate matters-only the sub-situations of s that are large enough to accommodate $\phi$ will be relevant.)
} 
c. Kogato majka mi vleze v stajata mi, az govoreh $\mathrm{s}$

When mother my came in room.the my, I talked.Impf with

gadžeto mi.

boyfriend.the my

d. Kiedy moja mama weszła do pokoju, ja rozmawiałam z moim When my mother came in room, I talked.Impf with my chłopakiem.

boyfriend

e. Kogda mama voshla $v$ moju komnatu, ya razgovarivala so svoim When mother came in my room, I Prefix.talked.Impf with my parnem.

boyfriend

'When my mother came into my room, I was talking (Impf) with my boyfriend.'

As with habituals/generics in Sect. 3.1, all the examples in the paradigm in (9) include IMPF. To briefly explain, the Romance sentences in (9a)-(9b) contain verbs in the Imperfect tense; Bulgarian (9c) contains an imperfective (i.e., unprefixed) verb inflected for the Imperfect tense; Polish (9d) contains an imperfective (i.e., unprefixed) verb inflected for the participial form that stands for the general past in many East and West Slavic patterns. Finally, Russian (9e) exhibits a participle verb, so a past, with the morphology of so-called secondary imperfectives; this verb roughly consists of a prefix followed by a verb stem, a secondary suffix, a participle marker, and a feminine singular ending: raz-govari-va-l-a.

Let us now turn to our proposal. In sentences like (9a)-(9e), the input situation is determined by the sentential context: the past situation of my mother entering the room. These sentences give rise to the intuition that the topic situation is in the middle' of a situation in which I am talking to my boyfriend. We propose to account for this interpretation with a MB that gives IMPF access to all subparts of the topic situation, as in (10).

$$
\mathrm{MB}_{\text {ongoing }}=\lambda \mathrm{s} . \lambda \mathrm{s}^{\prime} \cdot \mathrm{s}^{\prime}<\mathrm{s} .
$$

Given (10), the domain of quantification of IMPF will consist of all the (relevant) subparts of the topic situation. Thus, if we let the input situation to IMPF be the situation of my mother entering the room, the truth conditions for (9a)-(9e) will be (11):

$$
\begin{aligned}
& \llbracket(9) \rrbracket^{c, g}=1 \text { iff } \\
& \forall s^{\prime}: M_{\text {ongoing }}\left(s_{\text {my mother enters the room }}\right)\left(s^{\prime}\right)=1, \\
& \exists e: \text { e is an event of me talking to my boyfriend in } s^{\prime} .
\end{aligned}
$$

As in other readings, the VP-predicate puts constraints on the granularity of the domain of quantification: quantification will only take place over sub-situations that are large enough to accommodate a VP-event. In (9a)-(9e), the topic situation is relatively small, so it will only be possible to have relatively homogeneous eventualities embedded under IMPF. If the nuclear scope eventuality is inherently large, it will not be possible to find subparts in the topic situation that can accommodate the VP-event, and quantification will be vacuous. Thus, ongoing interpretations with small topic 
situations will only be available with eventualities of very fine granularity: states, fine-grained activities. Of course, if the topic situation is not large enough to include an eventuality corresponding to the VP, one may still be able to felicitously interpret an Imperfective in relation to other MBs, such as Event-inertia to be discussed in Sect. 3.3.

It is interesting that the only eventualities small enough to fit into small topic situations are very homogeneous or fine-grained. Homogeneous eventualities, having the subinterval property, are the right kind of eventuality to distribute over a (small) topic situation, but they are also the right kind of situation to expand around a topic situation. Consider (9) again. If all subparts of the situation of my mother entering the room are situations in which I was talking to my boyfriend, it is likely that I was talking to my boyfriend before my mother came in. This is not required by the truthconditions of (9a)-(9e) in (11), which only care about the topic situation. But, especially in the case of small topic situations, it will be quite natural to find homogeneous eventualities overflowing the topic situation, and expanding past its borders. This will give rise to the intuition that the temporal location of the topic situation (equivalent to the reference time in other frameworks) is included within the temporal location of the event (the event time in other frameworks), the classic characterization of imperfective viewpoint aspect. In the proposal made here, this temporal relation is not directly required by the truth-conditions of (9a)-(9e), but instead arises because, with small topic situations, it is quite natural to find homogeneous eventualities expanding past the topic situation (and, remember, homogeneous eventualities will be necessary for universal quantification to felicitously lead to truth).

Notice that generic readings end up being a special case of ongoing readings: i.e., with quantification over subparts restricted to those with certain modal properties (normal or characteristic). In this view, generic readings are iterative readings of a certain kind. In what would be technically the most unrestricted case, when the topic situation is the whole world, generic readings would involve universal quantification over all characteristic sub-situations in the world, while ongoing readings would involve universal quantification over all situations in the world (a very unlikely domain of quantification). Plausibly, the difference between generic and ongoing readings will only be relevant when the topic situation is large enough to distinguish between regular and normal parts. It may be that with very small topic situations (i.e., my mother coming into the room in (9)), it is not normally possible to distinguish normal subparts, in which case, a generic reading will not normally arise.

\subsection{Events in progress vs. events in preparation and IMPF: a first contrast}

In this section we investigate a first instance of cross-linguistic variation in the interpretation of IMPF, centered on readings associated with the traditional notion of 'Inertia'. We argue that such readings may be of two types, which do not distribute equally across Romance and Slavic. Let us begin with a first type of inertia reading in the paradigm in (12):

(12) a. El perro cruzaba la calle cuando lo atropelló un autobús.

The dog crossed.Impf the street when it run.over a bus 
b. Le chien traversait la route, quand il s'est fait écraser par The dog crossed.Impf the street when he Refl was made run.over by un autobus.

a bus

c. Kučeto presičase pătja, kogato avtobusăt go blăsna. Dog.the crossed.Impf road, when bus it run.over

d. Pies przechodził przez ulicę i został uderzony przez autobus. Po Dog crossed.Impf across street and was.struck by bus

e. Sobaka perebegala dorogu kak na nejo naexal avtobus. Ru Dog crossed.Impf road as to him run.over bus

'The dog was crossing (Impf) the road/street when/as it was run over by a bus.'

As before, all verbs in (12) display the morphology characteristic of imperfectives in the temporal/aspectual systems of the relevant language.

We understand the paradigm in (12a)-(12e) as telling us that at some contextually given past time, the dog was actually crossing the street/road, without commitment to completion. We also understand that if the VP-event in (12a)-(12e) had developed normally without interruptions, the dog would have successfully crossed the street/road.

Dowty (1979) proposed a semantic analysis of the parallel so-called Imperfective Paradox interpretation in English progressives based on inertia-worlds, which has been the source of much fruitful research and discussion (Landman 1992; Portner 1998, among many others). In our situation-based proposal, we view such inertia readings in terms of inertia-situations inspired by Cipria and Roberts (with differences). The notion 'inertia-situation' is relational: for the relation to hold between $s$ and $s^{\prime}, s^{\prime}$ must be a normal continuation of $s$. This means that $s^{\prime}$ must include s (via counterparts as in Sect. 2.2), and must have a temporal dimension that goes beyond that of $s$ into the future. The development of $s^{\prime}$ must be normal, meaning by this that $\mathrm{s}^{\prime}$ must not only obey the natural laws of $\mathrm{s}$, but also the expected pattern of development of s. (Things that happen in $\mathrm{s}^{\prime}$ are not exceptional-there is obviously a context-dependent evaluation implicit in this notion.) Inertia situations $s^{\prime}$ will serve to cash out the normal consequences of what is already going on in s. The intuition behind such an inertia analysis of IMPF is that there is something actually happening that, in normal circumstances, will lead to the truth of the embedded clause. ${ }^{14}$

Cipria and Roberts (2000) appeal to inertia-situations to account for two uses of Imperfectives in Spanish: events that are incomplete but in development at the past topic situation (which we dub 'events in progress') already illustrated in (12a), and events that are only in the planning stage at the past topic situation, which we illustrate in (13).

\footnotetext{
${ }^{14}$ Since Dowty, many have noted difficulties in pinning down the notion 'inertia world' (see most notably Landman 1992; Portner 1998). We will not attempt to deal with this problem here, and talk simply about normal, expected continuations of situations.
} 
(13) La semana que viene viajábamos a Paris, pero han cancelado

The week that comes traveled.Impf.1Pl to Paris, but have.3Pl canceled el viaje.

the trip

'Next week we were traveling (Impf) to Paris, but they have canceled the trip.'

Sentence (13) displays a type of Imperfective we dub 'Intentional' in tune with Cipria and Roberts (also known as 'futurate' in the literature), and tells us that we were scheduled to travel, without commitment to actual traveling. Cipria and Roberts (2000:328) propose to assimilate cases like (13) to cases like (12a), with the idea that events of traveling include the preparations for the event. They build on Moens and Steedman's (1988) preparatory process for an event viewed as "a subpart of the event before any culmination (of the change of state) occurs, during which preparations for its occurrence are complete." Given Cipria and Roberts' extension, IMPF quantifies over situations that extend the actual beginning of an event corresponding to the VP both in (12a) and (13).

We will not adopt Cipria and Roberts' treatment of Intentional Imperfectives. As noted in Sect. 1, there is cross-linguistic variation between ongoing and what we dub intentional readings for Imperfectives. On the one hand, in both Romance and Slavic, Imperfectives are generally used to depict events in progress in prototypical imperfective paradox contexts, as in (12a)-(12e). On the other hand, Imperfectives of the intentional/futurate type such as (13) are less general, so they offer a different cross-linguistic picture.

Intentionals are common in Romance, and routinely mentioned in traditional grammars and the recent literature (though their analysis remains a major topic of debate). ${ }^{15}$ By contrast, the Slavic tradition does not contemplate Intentional Imperfectives, and they are considered unavailable in the rare occasions they are mentioned (Dočekal and Kučerová 2009:128(6), when discussing Czech). Building on Rivero and Arregui (2010, 2012), in this paper we propose a more nuanced position. In a traditional vein, we maintain that Intentional Imperfectives are not available/grammatical in West and East Slavic. However, in contrast with traditional views, we argue in favor of Intentionals in South Slavic, albeit under different conditions depending on the language. On the one hand, Intentionals are generally available in at least Bulgarian (we do not examine Macedonian), and found (a) with several Vendlerian verb classes in Indicative Mood sentences illustrated in this section, (b) with imperfective (participles) in several Vendlerian classes in the Renarrated Mood illustrated in Sect. 6.1, and (c) with desiderative Involuntary States illustrated in Sect. 6.2, also with a variety of Vendlerian verbs/VPs. Intentionals, however, seem less general in other South Slavic languages. In Slovenian in particular, they are restricted (a) to sentences with (determinate/indeterminate) motion verbs traditionally considered inherently imperfective, as in (14b), and (b) to desiderative Involuntary States illustrated in Sect. 6.2. (Slovenian differs from Bulgarian in lacking a Renarrated Mood.)

\footnotetext{
${ }^{15}$ Ippolito (2004), Giorgi and Pianesi $(2001,2004)$ on Italian; Rodríguez (2004) on Spanish, among many others in Romance.
} 
In this paper, we attribute the contrast in grammaticality depicted in (14a)-(14c) to the presence/absence of Intentional Imperfectives. On the one hand, Bulgarian (14a) and Slovenian (14b) are well formed in South Slavic, while Polish (14c) representing West Slavic is deviant. These are all imperfective equivalents examples with motion verbs equivalent to Spanish (13). ${ }^{16}$ In addition, sentences (14d), (14e) and (14f) serve to illustrate that these three languages exhibit parallel identifiable morpho-syntactic structures to express intentional readings by means of additional modal categories. To briefly explain, Bulgarian (14a) contains a verb in the Imperfect. Slovenian (14b) contains a morpho-syntactic form of the general past in imperfective form that differs in shape from the general past in East and West Slavic: roughly, it consists of a beauxiliary to encode Past, and a participial verb that encodes imperfectivity. Given that this language lacks both Aorist and Perfect tenses, (14b) stands for an imperfective

${ }^{16}$ As stated, Bulgarian Intentionals are grammatical with several types of Vendlerian verbs so are not restricted to motion verbs, while Slovenian Intentionals are restricted to such verbs, leading to contrasts such as the one depicted in (i.a) vs. (i.b) in contexts such as A-B.

A: It's a pity the cinema had to close because of fire hazards.

B: (Yes.) Tomorrow they were showing Avatar.
a. Utre davaxa Avatar.
Tomorrow give.Impf Avatar
'Tomorrow they were giving (=showing) Avatar.'
b. *Jutri je igral Avatar.
Tomorrow Past.Aux.3Pl play.Impf Avatar
c. Jutri naj bi igral Avatar.
Tomorrow Mod.Part Cond.Aux play.Impf Avatar
'Tomorrow they would be showing Avatar.'

Bulgarian

Slovenian

Slovenian

In Bulgarian (i.a), the Imperfect verb davaxa 'they were giving' contributes an intentional reading without there being any (additional) overt modal constituent in the clause. By contrast, the Slovenian past imperfective periphrasis je igral 'they showed.Impf' is deviant in (i.b). However, the conditional auxiliary $b i$ in combination with the modal particle naj added to the imperfective verb in (i.c) makes the structure grammatical with the relevant intentional reading. This shows that the intentional reading of Slovenian (i.c) is due to the compositional effect of the particle and the conditional auxiliary, not to the imperfective morphology on the verb.

Although the topic requires much future research, we could perhaps account for the Slovenian contrast between (14b) and (i.b) by adopting the idea of Kagan (2007), who argues that the structure of motion verbs that participate in the determinate-indeterminate distinction in (some) Slavic languages contains an IMPF operator. We could then propose that the Slovenian verb in (14b) contains such an operator, which accesses the Preparatory-inertia MB in (16), among other available MBs. On this view, intentional readings would be possible with many types of Vendlerian verb classes in Bulgarian, but they would be restricted to motion verbs in Slovenian. We consider the contrast assigned here to the availability/unavailability of Intentionals between Slovenian (14b) and Polish (14c) significant (to eliminate competition accounts, for instance), because these two languages share parallel temporal systems. Similarities between the two include (a) only one general Past, without Imperfect, Aorist, or Perfect tenses, (b) parallel determinate-indeterminate distinctions for motion Vs traditionally considered inherently imperfective, a dichotomy absent from Bulgarian, and (c), as we just showed, alternative means to express intentional readings. In Sect. 6.2, we argue that the semantic contrast between Involuntary States in Polish vs. Slovenian further motivates the proposed distinction: namely, Slovenian exhibits Intentional Imperfectives, which may sustain a desiderative reading, while Polish offers no Intentionals, so its Involuntary States lack a desiderative reading. In our view, Russian patterns with Polish, for reasons given in footnotes 21 and 36. The crucial point for the general program of this paper, however, is that there are Slavic languages with Intentional Imperfectives, and Slavic languages without, but finer distinctions may be uncovered upon further research. 
general past, not for an imperfective Perfect. Polish (14c) contains the past imperfective verb we already introduced for generics/habituals. In (14d)-(14e), we partially illustrate grammatical alternatives that also express intentional-like meanings by different morphological means. They all contain overt modal constituents roughly comparable to English would, each within the specific morpho-syntactic conditions of the language in question: Bulgarian štjaxme with a sentential complement that contains the inflected lexical verb, the Slovenian modal particle naj combined with the conditional auxiliary $b i$ and the participial verb, and the Polish inflected modal verb mieliśmy with the lexical verb in the infinitive. Similar comments would apply to Intentional Imperfectives in Romance in so far as they also alternate with grammatical constructions with overt modals and intentional readings, which we do not illustrate.

(14) a. Sledvaštata sedmica pătuvaxme do Pariž, no imaše stački i

Next.the week traveled.Impf.1pl to Paris, but were strikes and otkazaxme pătuvaneto. canceled.1pl trip.the

b. Še do včeraj smo nasledji teden potovali v Pariz, vendar Still to yesterday Past.aux.3pl next week travel.Impf to Paris, but so tam stavke in smo potovanje odpovedali. are such strikes and Past.aux.3pl trip canceled.pl

c. *Jechaliśmy do Paryża w przyszłym tygodniu, ale teraz są tam Traveled.Impf.1Pl to Paris on next week, but now are such strajki więc odwołaliśmy podróż. strikes that we.canceled trip Intended: 'We were traveling to Paris next week, but there are (such) strikes, and we canceled the trip.'

d. Štjaxme da pătuvame do Pariž sledvaštata sedmica, no .... B B Would.1pl. to travel.1pl. to Paris next.the week, but....

e. Naslednji teden naj bi obiskali Pariz, Next week Mod.Particle Conditional.Aux visit.Pf Paris, vendar... but ...

f. Mieliśmy jechać do Paryża w przyszłym tygodniu, ale ... Would.1pl travel to Paris in next week, but... $(14 \mathrm{e})-(14 \mathrm{f})=$ 'We would travel to Paris next week, but ...'

It follows from the paradigm in (14) that Bulgarian and Slovenian functionally equivalent structures such as those in (14d)-(14e) alternate with well formed Imperfectives, which is not the case in Polish, since (14f) is well formed and (14c) is deviant.

The paradigm in (14a)-(14c) shows that not all languages that have Imperfectives for incomplete events also have intentional Imperfectives, even when they all have additional comparable morpho-syntactic means within their TAM systems to express related meanings, as in (14d)-(14f). This situation leads to the conclusion that the 
choice of Intentional Imperfectives is independent of the choice of Imperfectives for events in progress- the crucial point. ${ }^{17}$

What are the theoretical consequences of the cross-linguistic variation illustrated above for an analysis of IMPF? In our view, such variation can serve as a crucial tool to restrict the role assigned to pragmatics in discussions on Imperfectives. First, if the identification of events systematically included their preparatory processes, we would not expect cross-linguistic variation of the above type. Second, variation would also be difficult to explain if the extension of an event to include its preparatory process were the result of (pure) pragmatic coercion, resulting in a more permissive identification of events. If a purely pragmatic effect were applied to ongoing readings to obtain intentional readings by pushing back the event so as to include a purely preparatory phase, as Cipria and Roberts (2000) seem to suggest, we would not expect the cross-linguistic variation observed above. ${ }^{18}$ The best scenario under a purely pragmatic approach is for languages to behave along parallel lines, contrary to fact. A pragmatic approach would force us to adopt the undesirable view that languages with similar characteristics such as Slovenian and Polish apply different principles of a deductive and conversational type to sentences with parallel morpho-syntactic properties as in (14b) and (14c). Third, pragmatic accounts based on competition, an option mentioned by our anonymous reviewers, do not seem suitable for Intentionals either. As we saw, the languages under consideration in this paper offer other available grammatical means within their TAM systems to express intentional readings. Still, we find a contrast in grammaticality, as Intentionals are possible in languages like Bulgarian (or in the Romance family), and to a lesser extent in Slovenian, but are ungrammatical in Polish, amongst other Slavic languages. Finally, we show in Sect. 5 that in Mẽbengokre there is a specific imperfective marker to lexically encode an intentional reading. This situation suggests to one of our reviewers that language families that display a lower semantic specificity in their morphological encoding of imperfectivity than Mẽbengokre could possibly leave more room to pragmatics in obtaining the rich variety of readings that Imperfectives display in their group, in particular the intentional interpretation now under discussion. However, we just showed that Polish is one of the languages in the Slavic family without intentional readings for imperfectives. Thus, we may conclude that intentional readings cannot simply be

\footnotetext{
${ }^{17}$ As is traditional in discussions of Imperfectives, we focus here on past tense examples, not present tense examples, where the contribution of aspect is unclear. It is well known that, irrespective of aspectual status, presents allow planned/scheduled (our intentional) interpretations in many languages. For instance, in English both the simple present and the present progressive allow for intentional interpretations, suggesting that present tense, not aspect, may be the crucial component. In East and West Slavic, the role of presents is further complicated by the well known fact that present inflections combined with perfective prefixes have future meanings, and may also be used for plans and schedules, which raises the issue of the relation of modality not only to presents, but to perfectives.

${ }^{18}$ Coercion was originally suggested by Moens and Steedman (1988), with an early example of its pragmatic use in French Imperfectives proposed by Smith (1991). Smith suggests that the Narratives we discuss in Sect. 4.2 involve a procedure that pragmatically extends the event to its totality, but does not develop the proposal in detail. A different use of coercion for aspectual transitions within Discourse Representation is a covert type-shifting operation in semantics triggered by null operators, as for the French Imparfait (de Swart 1998, 2011, a.o., and critiques in Bonami 2002; Labelle 2003; a.o.). In such a semantic coercion approach, IMPF lacks semantic content, and readings result from various null coercion operators in the clause, reminiscent of the Slavic view that IMPF is semantically unmarked.
} 
the result of an inferential process sensitive to specific properties of the context combined with the lower semantic specificity for IMPF in Slavic (and mutatis mutandis in Romance).

The view we defend here is that IMPF shares the unitary semantic architecture in (5), but variation may arise in its readings because the grammar of some languages makes certain accessibility relations unavailable to IMPF, though those may be available in other languages. Our proposal, then, provides semantic (grammaticalized) explanations for the variation under discussion, but the logic of our approach does not imply that pragmatics could have nothing to say about the interpretation of Imperfectives. We are claiming that there is nothing special about Imperfectives from a pragmatic point of view. Pragmatic reasoning will have as much to say about the interpretation of Imperfectives as it has to say about the interpretation of other tense/aspect forms.

We propose that the differences identified in (13) and (14a)-(14b) in contrast with (14c) are encoded in semantics directly via a more fine-grained notion of inertia (a proposal to be taken up again for Mẽbengokre in Sect. 5, and when IMPF interacts with other operators in Slavic in Sect. 6). We propose to distinguish between two types of inertia: Event Inertia and Preparatory Inertia. Readings traditionally associated with the imperfective paradox arise when IMPF quantifies over situations made available via inertia MBs of type (15), and intentional/futurate readings result from MBs of type (16). ${ }^{19}$

\footnotetext{
${ }^{19}$ Note that Preparatory-inertia in (16) does not involve agentivity, so that sentences both with agentive and non-agentive subjects are parallel for our purposes. In this connection, an anonymous reviewer ponders if Russian examples of type (i) with non-agentive subjects contain Intentional Imperfectives.
}

(i) Poezd ukhodil v 5

$\mathrm{Ru}$ train left.Impf at 5

'The train would leave at 5.'

This topic requires further research, but we tentatively submit that Russian is amongst the languages that altogether lack Intentionals, with (i) belonging amongst habituals/generics in Sect. 3.1. As this reviewer points out, the verb in (i) is a secondary imperfective, and, we add, secondary imperfectives may have habitual readings across the Slavic family without apparent variation. In this way, Imperfectives in (i) should be compared to Romance Imperfectives such as Sp (ii), roughly glossed as 'would'/'used to'.

(ii) El tren salía a las 5 .

The train left.Impf at the 5

'The train would/used to leave at 5 .'

Further evidence for the generic flavor of Russian (i) comes from the addition of a deictic such as zavtra 'tomorrow', which renders the sentence ungrammatical. By contrast, adding the deictic mañana 'tomorrow' to Spanish (ii) results in a grammatical sentence with the futurate reading we call intentional: 'Tomorrow, the train was leaving at five.' In this paper, we attribute the above contrast between Russian and Spanish to the respective absence vs. presence of Intentional Imperfectives. Intentional Imperfectives allow for deictic anchoring.

The Russian sequence in (iii) we borrow from Grønn (2003:85(118)) is also mentioned by this reviewer as a second case where Imperfectives could potentially be intentionals.

(iii) Aukcionnyj torg otkryvalsja (IMPF) v pjat' časov.

Dostup graždan dlja obozrenija veščej načinalsja (IMPF) s četyreč.

Druz'ja javilis' (PERF) v tri [...] 
(15) Event Inertia

$\mathrm{MB}_{\mathrm{E}-\text { inertia }}=\lambda \mathrm{s} . \lambda \mathrm{s}^{\prime} . \mathrm{s}^{\prime}$ is an Event-inertia situation for $\mathrm{s}$, where for any two situations $\mathrm{s}$ and $\mathrm{s}^{\prime}, \mathrm{s}^{\prime}$ is an Event-inertia situation for $\mathrm{s}$ iff all the events that have actually started in s continue in $s^{\prime}$ as they would if there were no interruptions.

(16) Preparatory Inertia

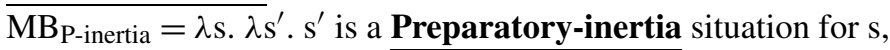
where for any two situations $\mathrm{s}$ and $\mathrm{s}^{\prime}, \mathrm{s}^{\prime}$ is a Preparatory-inertia situation for $\mathrm{s}$ iff all the events that are in preparatory stages in s continue in $s^{\prime}$ as they would if there were no interruptions.

The MB in (15) is 'modal' given that an event in s can be said to continue in s' only if $s^{\prime}$ has as part an event with beginning stages that have counterparts in s. Similarly, in MB (16), preparations for an event in s continue in $s^{\prime}$ only if $s^{\prime}$ has as part an event with preparations that have counterparts in s. Counterparts may be part of the evaluation world, but they may also be part of other possible worlds. Given a characterization of the continuations of events/preparations via counterparts, these two MBs allow IMPF to access situations in worlds that are not the evaluation world. Imperfective sentences will be true even though the culmination of the event is found in other possible worlds. In this way, we obtain the well-known 'modal' flavor associated with events-in-progress and events-in-preparation readings.

The proposals in (15)-(16) assume that, given a situation s, it is possible to distinguish between the events that have actually started in s, and preparatory stages for events. There is much discussion in the literature regarding the difficulties in doing this (Portner 1998; Cipria and Roberts 2000; Deo 2009, etc.). One difficulty is that preparations for events are also events, suggesting that inertia-types need to be calculated in relation to event predicates. However, we will make the simplifying assumption that events and preparations are distinct and keep (15) and (16) in the text, leaving a more technical discussion of inertia for future work. ${ }^{20}$ We trust that

'The auction was scheduled (literally opened) for $5 \mathrm{pm}$.

The inspection of the items was to start (literally started) at $4 \mathrm{pm}$.

The friends came at 3 pm.'

In our view, the two (secondary) Imperfectives in (iii) may also be analyzed in terms of characteristic/normal situations, with IMPF thus accessing the generic MB in Sect. 3.1. In the narrative sequence in (iii), the plot 'regresses' instead of advancing. We show in footnote 29 that Slavic and Romance habituals may advance (or mutatis mutandis 'regress' the narration), which also makes the Imperfectives in (iii) suitable habituals.

Rivero and Arregui (2012) argue in detail that the semantics of Involuntary States mentioned briefly in Sect. 6.2 in this paper also place Russian amongst the Slavic languages without Intentional Imperfectives (i.e., Preparatory-inertia is not available to IMPF in this language), a point we revisit when we discuss Involuntary States.

${ }^{20}$ The puzzle is reminiscent of problems discussed by Portner (1998) for English progressives as circumstantial modals. Portner claims that the circumstantial MB can only be properly identified in relation to an event and an event predicate. In a similar spirit, we speculate that Event- and Preparatory-inertia could be relativized to an event predicate as in $\left(15^{\prime}\right)-\left(16^{\prime}\right)$, with $\mathrm{MB}$ sensitive to whatever event predicate $\mathrm{Q}$ is embedded by IMPF. 
the intuition is clear enough to meaningfully talk about inertia for events as opposed to inertia for preparations for events. The important point is that languages may allow IMPF to access one type and not the other, and thus one cannot be considered a pragmatically derived re-interpretation of the other.

Let us consider the event-in-progress paradigm in (12) in view of (15). The LF of these imperfective sentences is in (17a) and truth-conditions are in (17b).

(17) a. [ past ${ }_{i}[\mathrm{IMPF}$ [the dog cross the road]]]

b. $\llbracket(17 \mathrm{a}) \rrbracket^{\mathrm{c}, \mathrm{g}}=1$ iff

$\forall \mathrm{s}^{\prime}: \mathrm{MB}_{\mathrm{E}-\text { inertia }}\left(\mathrm{s}_{\mathrm{i}}\right)\left(\mathrm{s}^{\prime}\right)=1, \exists \mathrm{e}$ : e is an event of the dog crossing the road in $\mathrm{s}^{\prime}$.

Here $\llbracket$ past $_{\mathbf{i}} \rrbracket^{\mathrm{c}, \mathrm{g}}=\mathrm{g}(\mathrm{i})=\mathrm{s}_{\mathrm{i}}$ (the salient $\mathrm{s}$ the sentence was about), and an event of the dog crossing the road is a complete event (i.e., the dog reaches the other side).

According to (17b), (17a) will be true iff all event-inertia situations for topic $s_{i}$ are situations in which the dog reaches the other side of the road. (Event-inertia situations will be normal continuations in which the events of crossing the road that have actually started reach their expected conclusion.)

Our proposal on Event-inertia correctly captures modal intuitions regarding incomplete events associated with examples such as (12a)-(12e) involving telic eventualities. These kinds of intuitions, however, could not be captured by the 'Ongoingevent' modal base in (10), which predicts that the topic situation contains event(s) of the dog crossing the road. Ongoing (10) and Event-inertia (15) make clearly different predictions for telic eventualities. But what would happen if instead of a telic eventuality, we had an atelic eventuality? For example, What would be the interpretation of examples of the type of Spanish El perro caminaba por la calle (cuando lo atropelló un autobus) 'The dog walked.IMPF on the street (when it was run over by a bus)'? If IMPF in this type of example is interpreted in relation to an Event-inertia MB such as (15), the sentence will be true only if the dog continues the stroll in the normal continuations of the topic situation (i.e., there is a modal dimension in the truth-conditions). If IMPF is interpreted in relation to an Ongoing-event MB as in (10), the sentence will be true only if the (relevant) sub-situations of the topic situation include an event of the dog walking on the street (i.e., there will be no modal dimension, as the claim is simply that there was walking going on when the dog was run over). Our proposal predicts that both claims can be made. It is natural to think that if the bus had not hit the dog, the dog would have kept on walking! But it is not necessary for truth. Suppose that the dog was trained to walk on the street until exactly 6 p.m. and then

$\left(15^{\prime}\right)$ Event Inertia

$\mathrm{MB}_{\mathrm{E}-\text { inertia }(\text { given } \mathrm{Q})}=\lambda \mathrm{s} . \lambda \mathrm{s}^{\prime} . \mathrm{s}^{\prime}$ is an Event-inertia situation for $\mathrm{s}$ given $\mathrm{Q}$.

$\mathrm{s}^{\prime}$ is an Event-inertia situation for s given Q iff all Q-events that have actually started in $\mathbf{s}$ continue in $s^{\prime}$ as they would if there were no interruptions.

$\left(16^{\prime}\right)$ Preparatory Inertia

$\mathrm{MB}_{\mathrm{P} \text {-inertia }(\text { given } \mathrm{Q})}=\lambda \mathrm{s} . \lambda \mathrm{s}^{\prime} . \mathrm{s}^{\prime}$ is a Preparatory-inertia situation for $\mathrm{s}$ given $\mathrm{Q}$.

$\mathrm{s}^{\prime}$ is a Preparatory-inertia situation for $\mathrm{s}$ given $\mathrm{Q}$ iff all Q-events that are in preparatory stages in $\mathbf{s}$ continue in $\mathrm{s}^{\prime}$ as they would if there were no interruptions. 
to freeze on the spot. If at 5:59 p.m. the dog is run over by a bus, a concerned individual could ask later: "What was the dog doing when it was run over by the bus?" The answer could be El perro caminaba por la calle ('The dog was walking on the street'). There is no presumption that the dog would have kept walking if the bus had not hit it. So even in the case of atelic eventualities, Ongoing and Event-inertia MBs are required in order to make correct predictions.

Let us turn to Preparatory-inertia in (16) for (14a), or Romance equivalents. The LF of these imperfective sentences is (18a) and the truth-conditions are in (18b):

(18) a. [ past ${ }_{\mathrm{i}}$ [IMPF [we travel to Paris next week]]]

b. $\llbracket(18 \mathrm{a}) \rrbracket^{\mathrm{g}, \mathrm{c}}=1$ iff

$\forall \mathrm{s}^{\prime}: \mathrm{MB}_{\mathrm{P} \text {-inertia }}\left(\mathrm{s}_{\mathrm{i}}\right)\left(\mathrm{s}^{\prime}\right)=1, \exists \mathrm{e}$ : e is an event of our traveling to Paris next week in $s^{\prime}$,

where $\llbracket$ past $_{\mathbf{i}} \rrbracket^{\mathrm{c}, \mathrm{g}}=\mathrm{g}(\mathrm{i})=\mathrm{s}_{\mathrm{i}}$ (the salient situation in which plans have been made regarding the trip).

Preparatory-inertia situations are those in which plans/preparations unfold normally. According to (18b), (18a) will be true iff all Preparatory-inertia situations for $s_{i}$ are such that we travel to Paris (if our past plans unfold normally, we travel to Paris next week). Intentional readings require quite marked contextual support: the topic situation must be a plan or preparation, and the VP eventuality must be something that can reasonably be planned or prepared given the context. In Preparatory-inertia, the topic situation is subject to very particular constraints, making the intentional reading available only in specific cases (i.e., there must be an awareness of a plan or that events have been set in motion more generally). In Preparatory-inertia, Imperfectives are used to talk about the content of plans or of what has been arranged/set in motion, so it might be tempting to attempt to reduce this kind of interpretation to other cases in which Imperfectives are used to talk about content, as in the case of movies, books or photographs. This, however, would not be a good move. Polish and Russian allow Imperfectives to describe the contents of movies, books and pictures (which we do not illustrate), but, as we have seen, not the contents of past plans.

Notice that in event inertia readings, the topic situation (reference situation) is part of a larger situation in which a VP-event takes place. The topic situation is thus included (via counterparts) within a larger situation corresponding to the VP-event. So even though the truth-conditions of the imperfective sentence are not formulated in terms of an inclusion relation between event and reference situation, inertia situations guarantee that the event situation includes the topic situation, and thus the time of the event will include the time of the reference situation. Indirectly, once again, we have ended up with the configuration typical of imperfective viewpoint aspect. ${ }^{21}$

In sum, in this section we identified a first instance of cross-linguistic variation affecting IMPF, as not all languages have Intentional Imperfectives. We proposed that this variation supports finer formal distinctions than traditionally assumed between

\footnotetext{
${ }^{21}$ Our semantics of Event- or Preparatory-inertia do not require that the relevant event not be completed in the actual world. However, Imperfectives interpreted in relation to inertia MBs often receive an incompleteevent reading. We preliminarily suggest that this is due to pragmatic reasons, leaving the topic to future research.
} 
events in progress and events in preparation, and encodes them into two different MBs, arguing that IMPF does not have access to one of those two MBs in some languages.

\section{Further variation: Slavic Factual Imperfectives and Romance Narrative Imperfectives}

This section continues our study of variation, comparing Slavic and Romance. We investigate a use known as Factual Imperfective, characteristic of some Slavic languages but not Romance, and a use characteristic of the Romance family seemingly absent in Slavic, known as Narrative Imperfect(ive). Factuals and Narratives, extensively discussed in the literature, have not usually been compared (Grønn 2008 is an exception), but are particularly interesting because both are used to report upon completed events, with the incomplete-event interpretation often associated with Imperfectives absent in their case. Thus, the challenge is to capture how in both Slavic and Romance, imperfectivity may in some instances give rise to a complete-event reading characteristic of perfectivity, albeit under non-identical guises. In Sect. 4.1 and Sect. 4.2, we explore how a modal analysis of IMPF could shed light on the well-known characteristics and less known differences of these two distinct uses of Imperfectives, but do not attempt to provide detailed analyses.

\subsection{Factual imperfectives in Slavic}

There is a perfective-like use of past Imperfectives in at least Russian and Polish that allows reference to a completed event, and has been compared to the English experiential Perfect (Borik 2002, 2006; Grønn 2003; Frąckowiak 2011). This use is known under traditional Russian labels such as Obshchefakticheskoe znachenie and Konstatacija fakta, or English labels that include Factual (Padučeva 1992), Statementof-Fact, and General Factual, and is illustrated by Russian (19a)-(19b) and Polish $(19 \mathrm{c})$.

(19) a. Petja uže peresekal etot kanal za polčasa.

Peter already crossed (Impf) this channel in half.an.hour

'Peter has already crossed this channel in half an hour.'

(Borik 2002:47)

b. Lena (uže) prinimala eto lekarstvo.

Lena (already) took (Impf) this medicine.

'Lena has (already) taken this medicine.'

(Kagan 2007)

c. Marcin malował juž obraz.

Marcin painted (Impf) already picture

'Marcin already painted a picture.'

(Frąckowiak 2011)

The so-called factual reading of the (bold) past Imperfectives in (19a)-(19c) has been much discussed in the literature, with most of the emphasis on Russian. ${ }^{22}$ It is claimed

\footnotetext{
${ }^{22}$ See Padučeva (1992) for discussion and references. Recent work includes a comparative study (Dickey 2000); Borik (2002), Grønn (2003), and Altshuler (2012) on Russian; Frąckowiak (2011) on Polish. Ar-
} 
to be available to past telic verbs of the accomplishment and achievement types, and, to repeat, its most significant dimension is to present events as completed. Sentence (19b), for instance, is not used to claim that at some past time Lena was in the process of taking this medicine, but rather, that the state or result of having taken the medicine was achieved in the past, and thus the event was completed in the past.

Padučeva (1992) notes the following properties for Factual Imperfectives in Russian: (i) their determining characteristic is to be resultative, denoting "an action that has reached a natural limit" (Padučeva 1992:114); (ii) they emphasize that something has actually happened; (iii) their result state does not usually continue until the moment of speech; (iv) the time of action is not presented as ordered with respect to the speech time, or as occurring at any specific time; (v) they have a retrospective point of reference, with events taking place in the past. Another property noted in the literature (Grønn 2008) is that Factual Imperfectives do not advance the reference time or narrative.

The resultative flavor of Factual Imperfectives has been viewed as important in the literature. Altshuler (2012) proposes to capture this dimension in terms of a multicoordinate approach according to which Russian Imperfectives play a double role, providing both temporal information and discourse-level information that locates a topic time within the consequent state of the event. ${ }^{23}$ In this paper, we also follow in the resultative tradition for the characterization of Factual Imperfectives. We propose that the factual reading arises for IMPF when the MB makes available for quantification the situations leading up to the topic situation (i.e., the preconditions for the topic situation/the situations whose consequences characterize the topic situation), and refer to this in (20) as a Resultative $M B$.

(20) $\mathrm{MB}_{\text {resultative }}=\lambda \mathrm{s} \cdot \lambda \mathrm{s}^{\prime}$. $\mathrm{s}$ results from $\mathrm{s}^{\prime}$, where for any two situations $s$ and $s^{\prime}, \mathrm{s}$ results from $\mathrm{s}^{\prime}$ iff $\mathrm{s}$ includes the consequences/results of the events in $\mathrm{s}^{\prime}$.

Given (20), IMPF will quantify over situations that have result-states in the topic situations. (As with other MBs in Sect. 3, the embedded predicate will play a role in identifying which kinds of events matter.) ${ }^{24}$ Given the MB in (20), a Factual Imperfective like (19b) will receive the truth conditions in (21b):

regui et al. (2011) note that Bulgarian restricts readings of type (19) to (compositional) perfectives, placing this language amongst those without Factuals, comparing it to Romance. Factual Imperfectives divide into groups; here we focus on the type Grønn (2003) dubs existential. They can also be classified as presuppositional (Grønn 2003) or actional (Padučeva 1992), characterized by information structure: they present presupposed information. However, it is unclear to us whether these represent a special type, and we leave them to future research.

${ }^{23}$ By contrast, Grønn (2003) argues that presuppositional Factual Imperfectives provide evidence against a resultative/experiential analysis. Frąckowiak (2011) develops an alternative analysis for Polish Factuals, focusing on discourse effects.

${ }^{24}$ As in inertia MBs in (15)-(16) in Sect. 3.3, it may be necessary to relativize the accessibility relation in (21), i.e., identify consequences in relation to a $\mathrm{Q}$ event predicate, as in $\left(21^{\prime}\right)$.

$\left(21^{\prime}\right) \quad \mathrm{MB}_{\text {resultative (given } \mathrm{Q})}=\lambda \mathrm{s} . \lambda \mathrm{s}^{\prime}$. s Q-results from $\mathrm{s}^{\prime}$, where for any two situations s and $\mathrm{s}^{\prime}, \mathrm{s}$ Q-results from $\mathrm{s}^{\prime}$ iff $\mathrm{s}$ includes the consequences of all Q-events in $\mathrm{s}^{\prime}$. 
(21) a. [past 1 [IMPF [ Lena takes this medicine]]]

b. $\llbracket(21 \mathrm{a}) \rrbracket^{\mathrm{g}, \mathrm{c}}=1$ iff $\forall \mathrm{s}^{\prime}: \mathrm{MB}_{\text {resultative }}\left(\mathrm{s}_{1}\right)\left(\mathrm{s}^{\prime}\right)=1$,

$\exists \mathrm{e}: \mathrm{e}$ is an event of Lena taking this medicine in $\mathrm{s}^{\prime}$.

According to (21), the Factual Imperfectives will be true iff all situations that have consequences in the topic situation include an event of Lena taking this medicine. The topic situation must be the result of a situation of Lena taking this medicine; so if the topic situation is a past situation of Lena having felt better, for example, this is predicted to be true iff her feeling better was the result of her having taken the medicine. The proposal in (21) allows for there to be multiple events of Lena taking her medicine that have consequences in the topic situation. This is in line with Padučeva (1992), who claims that factual imperfectives are unspecified regarding the number of times that the VP-eventuality has taken place (i.e., they allow for multiple events). This issue is also discussed by Grønn (2003), who claims that factual imperfectives make reference to single events, but allow for iteration-a proposal that is descriptively compatible with the predictions for (21a). Universal quantification over the situations that have results in the topic situation correctly captures the intuition that, if the topic situation were not the result of Lena taking this medicine, the sentence would be false (i.e., if Lena felt better for other reasons). This would not be predicted if existential quantification were associated with factuals, instead of universal quantification.

In Factual Imperfectives, both the result state and the VP-event are actual: i.e., in (19b) we understand that Lena did actually take her medicine. We can account for this if the result-relation in (21) is taken to only hold between world-mate situations (that is, a situation can only include the results/consequences of situations in the same world). We will take this approach here (and assume an additional world-mate condition in (20)) but note that it would also be possible to allow the result-relation to hold between situations in different worlds, as long as quantification was restricted to normal situations with results in the topic situation (that is, situations that are like actual situations with respect to relevant features, like causal laws, etc.). The decision to allow the domain of quantification of IMPF to include situations in other worlds depends on whether factual readings do indeed have modal flavors. We leave this issue for further research.

In our approach, there is great similarity between the Resultative MB in (20) and the Preparatory-inertia MB in (16) in Sect. 3.3. In the Resultative MB in (20), the topic situation cashes out the results of events that occurred earlier. In a sense, this Resultative MB is the mirror image of the Preparatory-inertia MB in (16). In Preparatory-inertia in (16), the topic situation contains the preparations for an event, and the situations quantified over contain the event. (The situations quantified over cash out consequences of the topic situation.) In the Resultative MB in (20), the topic situation contains the results/consequences of the event, and the situations quantified

According to $\left(21^{\prime}\right)$, the resultative relation will pay attention to the specific event predicate relevant in a particular sentence. In the text, we adopt the simpler proposal in (21), but acknowledge remaining open issues by presenting $\left(21^{\prime}\right)$ here. 
over contain the event. (The topic situation cashes out consequences of situations quantified over.)

Our proposal for IMPF combined with (21) allows us to make sense of many properties traditionally noted for Factual Imperfectives, capturing their resultative character. That the event reported by the Factual Imperfectives is not tied to a definite point in time, for instance, follows from the assumption that the sentence makes a claim about the resulting situation, and not about the originating event.

It is less clear how our proposal accounts for why Factual Imperfectives do not advance the reference time/narrative, a contrast with Romance Narrative Imperfectives in Sect. 4.2. But if we adopt the view that in order for the time of an event to serve as reference time the completion of the event must be within the topic situation, then it becomes clear that Factual Imperfectives will not advance the reference time. In Factual Imperfectives, there is a quantificational claim that in all situations with consequences in the topic situation, there is an event with certain properties. However, no specific VP-event is located in a time that could serve as future reference time.

Following in the tradition of resultative analyses for Factual Imperfectives, our proposal is comparable to Altshuler's (2012) proposal in paying attention to the state resulting from the VP-event. ${ }^{25}$ However, whereas Altshuler proposes to combine both temporal (event-in-development) information and resultative information in IMPF, we have chosen to distinguish the two types of information as arising from two distinct MBs that are both available to IMPF in Russian and Polish, but not both available to IMPF in Romance or Bulgarian. The approach we adopt gives us a better understanding of the cross-linguistic picture, since the two types of meanings can be dissociated: IMPF can have the temporal meaning without the resultative meaning. Separating the resultative from the temporal dimension also provides us with a better understanding of precise differences between some Slavic languages and the Romance family. On the one hand, we saw in Sect. 3.3 that both families have Imperfectives for events in progress associated with the Event-inertia MB in (15). On the other hand, whereas some Slavic languages make available Resultative MBs such as (20), allowing for quantification over the past situations leading up to the topic situation (thus display Factual Imperfectives), Romance languages generally make available Preparatory-inertia MBs as in (16), allowing for quantification over situations that expand the topic situation into the future (thus share Intentional Imperfectives). This cross-linguistic picture further argues against a view according to which the various interpretations of Imperfectives should be understood in terms of competition with more specialized forms. So far, we have seen that Russian and Polish Imperfectives give rise to factual readings in apparent competition with perfectives, but not to intentional readings, while Romance Imperfectives (as well as Bulgarian and, in limited cases, Slovenian) give rise to intentional readings in apparent competition with conditionals and modals, but not factual readings.

An anonymous reviewer suggests that competition may account for why there are no Factuals in the Romance family and Bulgarian, in contrast with Russian and

\footnotetext{
${ }^{25}$ We have not attempted to do justice to Altshuler's proposals here, which include interactions between Imperfectives and adverbs, and discourse effects. See also Grønn (2003) for an alternative analysis taking into consideration adverbs and rhetorical relations.
} 
Polish; that is, the idea is that the Romance languages and Bulgarian display Perfect Tenses, which would thus prevent Imperfects from displaying a factual reading. However, our cross-linguistic perspective proves useful to show that this suggestion may not be on the right track. Czech is one of the Slavic languages without Perfects, but Dickey (2000) tells us that it also lacks Factual Imperfectives.

In the next section, we consider Narrative Imperfects, which in Romance also compete with perfectives.

\subsection{Romance Narrative Imperfectives}

A well-known and much discussed use of Imperfects characteristic of Romance known as Narrative has a perfective-like reading, and alludes to complete events, as (22a)-(22d) illustrate with Spanish and French, adapted from the literature. Parallel examples could be given in other Romance languages, as this use seems widespread. ${ }^{26}$
a. Al amanecer salió
el regimiento, atravesó
la
At.the dawn went.out (Perf) the regiment, crossed (Perf) the montaña, y poco después establecía contacto con el enemigo. mountain, and little later established (Impf) contact with the enemy

(Reyes 1990)

'At dawn, the regiment went out (Perf), crossed (Perf) the mountain, and a little later established (Impf) contact with the enemy.'

b. Ayer moría Borges en Ginebra. (adapted from Reyes 1990) Yesterday died (Impf) Borges in Geneva 'Yesterday Borges died (Impf) in Geneva.'

c. A huit heures, les voleurs entraient dans la banque, ils At eight hours, the robbers entered (Impf) in the bank, they discutaient avec un employé, puis se dirigeaient vers le discussed (Impf) with an employee, then Refl directed (Impf) towards the guichet principal. window main 'At eight, the robbers entered (Impf) the bank, they discussed (Impf) with a clerk, then they moved (Impf) towards the main desk.' (adapted from Jayez 1999)

d. En 1492, Christophe Colomb découvrait l'Amérique. In 1492, Christopher Columbus discovered (Impf) the America 'In 1492, Columbus discovered (Impf) America.'

(Labelle 2003)

The bolded Imperfects in paradigm (22) bear a resemblance to Spanish and French aoristic 'perfective' Tenses known as Pretérito and Passé Simple, which would also

\footnotetext{
${ }^{26}$ The use in (22) is also known under French labels such as 'historique', 'de rupture', 'de perspective', 'pictoresque', and equivalents in other languages (including Italian 'cronistico' and Spanish 'citativo'). Considered literary and journalistic, it is grammatical and interpretable, the crucial point. Some French grammars subdivide Narratives into several types (Riegel et al. 1994/1998), and others view them as unitary (Togeby 1982), but we abstract away from such differences.
} 
be grammatical in similar contexts (thus suggesting that a pragmatic approach based on competition may not be suitable for Narratives, much like it fails in the case of Intentionals in Sect. 3 or, we suggested, Factuals in Sect. 4.1).

As their primary label suggests, Narrative Imperfectives are characteristic of reports and narrations, and, to repeat, are special in that they are used to report an event understood as completed, thus resembling Slavic Factual Imperfectives in Sect. 4.1. Sentence (22b) with the achievement verb die, for instance, is a piece of news that speaks of Borges' death as a culmination, not of the process that led to his dying.

While Narrative Imperfectives are similar to Factual Imperfectives in reporting complete events, they are importantly different with respect to at least two properties noted by Grønn (2008). First, Factual Imperfectives are not tied to a definite point in time (Padučeva 1992), while Narrative Imperfectives most often are, as (22) illustrates. Such a contrast proves significant for our proposal later, and we submit that it is the main cause of why Polish (23) sounds extremely odd (E. Frąckowiak p.c.) when compared to its completely natural Narrative counterpart in (22b). This also seems to be the reason why Russian examples parallel to (22d) may be cited as ungrammatical on discussions on imperfectives.

(23) ??Wczoraj Borges umierał w Genewie.

'Yesterday Borges died (Impf) in Geneva.'

A second difference concerns narrative advancement. As discussed in Sect. 4.1, Factual Imperfectives do not advance the reference time in narratives. Narrative Imperfectives, however, do: $(22 \mathrm{c}) .^{27}$

An additional contrast between Factuals and Narratives concerns Vendlerian classes. A preference for achievements is sometimes noted in the literature on Nar-

\footnotetext{
${ }^{27}$ In narrations and elsewhere, sequences of habitual events are systematically encoded by Imperfectives in both Romance and Polish (or Russian), as French (i) and Polish (ii) illustrate, and belong amongst the uses analyzed in Sect. 3.1. Since there is no contrast, in narratives, habituals should be distinguished from onetime events, where Narrative Imperfectives are fine in Romance, (22), while Polish and Russian demand perfectives to advance the narration.
}

(i) Chaque mardi, Jean déjeunait chez sa grand-mère. Il partait du bureau à Each Tuesday, J. lunched (Impf) at his grandmother. He left (Impf) from.the office at onze heures. Il passait par la patisserie et achetait un gateau. Il arrivait eleven hours. He went (Impf) by the pastry.shop and bought (Impf) a cake. He arrived (Impf) à onze heures et demie pour préparer le repas. at eleven hours and half to prepare the meal. 'Every Tuesday, Jean had (Impf) lunch with his grandmother. He left (Impf) his office at eleven. He stopped (Impf) at the bakery to buy a cake. He arrived (Impf) at half past eleven to cook the meal.' (Bonami 2002)

(ii) W każdy wtorek Jean jadł obiad ze swoja babcią. Opuszczał biuro o jedenastej. In each Tuesday J. ate (Impf) lunch with his grandma. Left (Impf) office at eleven. Zatrzymywał się w piekarni żeby kupić ciasto. Przychodził do domu o w pół do Stopped (Impf) Refl at bakery in.order.to buy cake. Came (Impf) to house at half before dwunastej aby gotować. noon in.order.to cook

'Each Tuesday, Jean ate (Impf) lunch with his grandma. He left (Impf) the office at eleven. He stopped (Impf) at the bakery in order to buy a cake. He arrived (Impf) at home at half to twelve in order to cook.' 
rative Imperfectives, but they may also appear with accomplishment verbs, and activities as in (22c), indicating complete events and advancing the narrative in each case. Narrative readings, then, are found with both telic and atelic events, while Factual readings in Sect. 4.1 are restricted to telic events. All the noted differences add up to make Polish (24) sound extremely odd (E. Frąckowiak, p.c.) while the parallel Romance Narrative in (22c) sounds natural.

(24) ??O ósmej rabusie wchodzili do banku. Rozmawiali z kasjerem About eight robbers entered (Impf) in bank. Talked (Impf) with cashier a potem ruszali $\quad$ w kierunku głównego stanowiska. Po and then moved (Impf) in direction main site ??'At eight the burglars entered (Impf) the bank. They talked (Impf) to a clerk and then they moved (Impf) towards the main stand.'

While Romance Narrative Imperfectives are similar to Factual Imperfectives in presenting an event as completed, in our view the two differ in so far as in Narratives the focus is not on the results of the event, but on the event itself. In Narrative Imperfectives, then, it is the culmination of the event that is topical, not its consequences. We propose to capture this interpretation with a MB according to which the topic situation includes the culmination of the events in the situations quantified over, as in $(25)$.

(25) $\mathrm{MB}_{\text {narrative }}=\lambda \mathrm{s} . \lambda \mathrm{s}^{\prime} . \mathrm{s}^{\prime}$ culminates in $\mathrm{s}$, where for two situations $s$ and $s^{\prime}, s^{\prime}$ culminates in $s$ iff all events in $s^{\prime}$ have their culmination in $\mathrm{s.}^{28}$

Given MB (25), IMPF will quantify over situations that have their culmination point in the topic situation. A Narrative Imperfective will be true iff the topic situation is such that it includes the culmination of an event of the type corresponding to the VP-predicate. As in the case of Factual Imperfectives, we restrict the domain of quantification to world-mate situations, stipulating that the culmination relation only holds between world-mate situations. (It remains for future research to investigate whether a modal approach would be better.) Let us apply our proposal to the fragment of French $(23 c)$ in (26) with the narrative reading whereby the robbers have reached the main desk, so the event is complete. (In this and other cases ongoing readings are, of course, grammatical.)

Russian and Polish obviously do allow the use of Imperfectives in narrations, but those do not obtain the complete-event interpretation typical of Romance Narrative Imperfectives, and do not advance the narration (i.e., Russian and Polish lack Narrative Imperfectives, or, in our terms, in these languages IMPF does not access the MB we propose in (25)).

${ }^{28}$ As before, it would be advisable to relativize culmination to a particular event predicate Q (the VPpredicate), as in $\left(25^{\prime}\right)$.

$\left(25^{\prime}\right) \quad \mathrm{MB}_{\text {narrative }}($ given $\mathrm{Q})=\lambda \mathrm{s} \cdot \lambda \mathrm{s}^{\prime} . \mathrm{s}^{\prime} \mathrm{Q}$-culminates in $\mathrm{s}$ where for two situations s and $\mathrm{s}^{\prime}, \mathrm{s}^{\prime}$ Q-culminates in $\mathrm{s}$ iff $\mathrm{s} \leq \mathrm{s}^{\prime}$ and all Q-events in $\mathrm{s}^{\prime}$ have their culmination in $\mathrm{s}$. 
(26) A huit heures, ... les voleurs se dirigeaient vers le guichet principal. 'At eight, ... the robbers moved (Impf) towards the main desk.'

Given MB (25), the truth-conditions for (26) are in (27). (We assume that à huit heures denotes eight o'clock on the relevant day, and provides a frame for the topic situation.)

(27) a. [at-eight-o'clock Past ${ }_{1}$ [IMPF [the robbers move towards the main desk]]] b. $\llbracket(25 a) \rrbracket^{c, g}=1$ iff $\mathrm{s}_{1} \leq \mathrm{s}_{\text {eight-on-that-day }}$ and $\forall \mathrm{s}^{\prime}: \mathrm{MB}_{\text {narrative }}\left(\mathrm{s}_{1}\right)\left(\mathrm{s}^{\prime}\right)=1$, $\exists \mathrm{e}: \mathrm{e}$ is an event of the robbers moving towards the main desk in $\mathrm{s}^{\prime}$.

Given (27b), (27a) will be true iff all situations that culminate in the topic situation are situations in which there is an event of the robbers going to the main desk. This will only be the case if the topic situation is the situation corresponding to the culmination of such an event. If the topic situation does not include the culmination of such an event, the Narrative Imperfective sentence will be false. (With VP-predicates that characterize punctual events such as achievements, quantification will only take place over the topic situation.) Universal quantification in IMPF ensures that in the case of narratives, the topic situation is presented as the culmination of VP-predicate-type events. (If quantification were existential, we would mistakenly predict that the topic situation could also be the culmination of events of a totally distinct type.) However, given the world-mate condition, it could be that the domain of the quantifier ends up being a singleton set (i.e., it could be that the topic situation was the culmination of a single event of the relevant type). This would presumably not happen if the domain of quantification was modal, but, as noted earlier, this remains for future research.

In Sect. 4.1, we established a partial parallelism between the Resultative MB for Factual Imperfectives in (20) and the Preparatory-inertia MB for Intentional Imperfectives in (16) in Sect. 3.3. In this section, a partial parallelism also arises between the Narrative MB in (25) and the Event-inertia MB in (15) in Sect. 3.3. While in Event-inertia, the topic situation includes the beginning of an event corresponding to the VP-predicate, in Narrative (25) the topic situation includes the culmination of a VP-event. In a sense, Narrative Imperfectives are the mirror image of Event-inertia Imperfectives. There is a difference, however, in terms of a dimension traditionally called 'modal': in Narrative Imperfectives, we understand that a VP-event has actually happened, whereas this is not true for Event-inertia Imperfectives (i.e., the imperfective paradox). In our proposal, the domain of quantification of IMPF consists of actual world situations that culminate in the topic situation, guaranteeing a factual reading of the VP-predicate. To some extent, differences between the Inertia MBs in Sect. 3.3 and the MBs for Factual and Narrative Imperfectives in Sect. 4 can be understood as an asymmetry in the domain of situations quantified over. In Inertia MBs, quantification takes place over lawful continuation situations, which may not be actual. In Factual and Narrative Imperfectives, it takes place over actual situations that lead up to the topic situation. There is thus an asymmetry between the way we identify situations looking towards the future and towards the past. The result is a factual reading of the VP in the second case.

The proposals in this section can help us make sense of the difference between Factual Imperfectives and Narrative Imperfectives regarding shifts in narrative time: 
in Narrative Imperfectives, the VP-event does culminate within the topic situation, and, we speculate, this makes it possible for the narrative time to move forward.

Our proposal can only be considered a promissory note for the semantics of Narrative Imperfectives. Our objective was to show a plausible analysis in terms of the machinery of MBs that gives us a handle on variation, as Narrative MBs will be available in some languages but not others. Our proposal to grammaticalize Narrative Imperfectives (and mutatis mutandis Factual Imperfectives, and thus variation) has an advantage over proposals that treat Narrative Imperfectives in terms of pragmatic coercion (Smith 1991; Labelle 2003 on French), which would have difficulties capturing why some languages disallow Narrative readings. Language-internal competition analyses do not fare well either, since Narratives in Romance compete with Aorists in some languages, with Perfects in other languages, and with both Aorists and Perfects still in other languages, or variants within a language, as in Spanish. In spite of the availability of other grammatical forms that can specifically target complete events within a narration, and move the narrative time forward, Narrative Imperfectives are able to take on this role.

A last point deserves mention before we conclude this section. In the literature on Romance, we find proposals according to which Imperfectives have no meaning of their own, and associate with silent operators, thus obtaining their interpretation from whatever operators they scope under (e.g. de Swart 1998, among several others). Our proposals for Romance and Slavic in Sect. 3 and Sect. 4 are quite different from such views, which immediately raises the question of whether the different interpretations we associate with Imperfectives could in fact belong to distinct operators that are phonologically null, and that imperfective morphology is semantically vacuous, chosen simply to allow those operators to shine through. Advancing ideas, we will offer evidence supporting our proposals in Sect. 6.1, when we examine the interaction of IMPF with other operators, and compare Romance Narrative Imperfectives and Bulgarian Imperfectives. In brief, Bulgarian has an overt evidential morphology traditionally known as the Renarrated Mood (RM) used for assertions grounded on indirect evidence (Izvorski 1997, a.o.), and it bears some similarities to Romance Narratives. However, the Bulgarian RM allows the whole range of interpretations available to IMPF to surface under its scope, and thus contrasts with Romance Narratives. This situation is telling for our purposes because it means that the evidential operator of the RM can scope over IMPF with all the interpretation this last operator may receive in Bulgarian. If we restricted our attention to just Narrative Imperfectives in Romance, we could perhaps be tempted to capture their interpretation in terms of semantically empty imperfective morphology associated with a null evidential-style narrative operator, similarly to what we find overtly in Bulgarian. However, if Romance Narratives contained a null version of an evidential operator, we would incorrectly expect them to allow such an operator to scope over other (null) operators that can associate with Imperfectives in Romance (namely, Preparatory-inertia, Eventinertia, generics, etc.), which is not the case. The argument, in summary, is that if the interpretation of Imperfectives depended on null operators, we would expect to see interpretations corresponding to the 'stacking' of operators we can see overtly in some languages, but we do not find these interpretations associated with simple imperfective morphology. At most one 'modal flavor' (not a combination of two or 
more) can associate with any one case of imperfective morphology. More complex interpretations, then, are cases in which we see imperfective morphology interacting with other, independently identified operators, as in the various constructions discussed in Sect. 6. This favors the view according to which imperfective morphology brings with it its own meaning.

\section{Mẽbengokre}

In this section, we turn to the expression of imperfective meanings in Mẽbengokre, a northern Jê language, with a different morpho-syntactic organization from Romance and Slavic. Mẽbengokre is spoken by the Xikrin and the Kayapó in central Brazil, and has currently around 10,000 speakers. It has not been much discussed in the aspect literature, so we provide some background information for our discussion. ${ }^{29}$ Data in this paper come from original field research, primarily among the Xikrin.

\subsection{Building imperfective readings in Mẽbengokre}

In Mẽbengokre, modal or aspectual notions are expressed by optional left-peripheral particles or by post-verbal elements, both illustrated in bold in (28).

(28) Amrẽbê nẽ ba karinhô jakôr $\mathbf{o}=\mathbf{n h} \mathbf{y}$.

long.ago NFUT 1NOM tobacco blow.N O=sit.V

'Long ago I was smoking.'/ 'I have been smoking since long ago.'

Left particles include ñe (nonfuture) in (28), dja (future), evidentials, frustratives, consequential, and consecutive connectives, and so on. Post-verbal elements, which are the focus of our discussion, include a series of items with progressive mean-


(imminent), jabej (possibility), kêt (negation), rã' $\tilde{a}$ (durative), etc. They allow some recursion in structured elicitation, but the only combination with any real frequency in spontaneous speech is the embedding of progressives under negation, possibility or durative.

The morpho-syntactic behavior of post-verbal elements is distinct from that of left particles. The first combine with a particular form of the lexical verb: the non-finite or nominalized form marked in our glosses by $\mathrm{N}$ (e.g., jakôr in (28)). Left particles may appear with all types of predicates. In particular, they may occur with nonnominalized verbs we gloss with $\mathrm{V}$ (only possible if post-verbal items are absent), as illustrated in (29) with $n \tilde{e}$.

(29) Kajtire nẽ arỳm mã tẽ.

Kajtire NFUT already away go.V

'Kajtire has left already.'

\footnotetext{
${ }^{29}$ For more information see Reis Silva and Salanova (2000), Salanova (2007, 2008), Salanova and
} Reis Silva (2011), and Salanova (2011). 
Following Reis Silva and Salanova (2000) and later work, we take nominalization to be an indicator of syntactic complementation. Thus, we propose that post-verbal elements are complement-taking heads, which, contrary to left particles, license subordinate structures. In particular, the post-verbal elements (discussed in more detail below) function as main predicates that take non-finite verbal clauses as complements they govern. (For negation and related items as predicates of nominalized clauses see Salanova 2007, 2008, 2011.)

We next provide two arguments that post-verbal elements such as $n h \tilde{y}$ in (28) behave as main predicates that take clausal complements in the syntax. First, in Mẽbengokre, constructions with post-verbal elements and constructions with perception and desiderative verbs display parallel syntactic structures, which supports our hypothesis that post-verbal items involve clausal subordination in syntax. The parallelism can be seen when comparing progressive (28) to the constructions with the verb pumũ 'see' in (30a), or the verb prãm 'want' in (30b) (complement clauses are in brackets).
a. Ba [aje tep krẽn] pumũ.
I.NOM [you.ERG fish eat.N] see.V
'I saw you eat fish.'
b. Imã [aje tep krẽn] prãm.
I.DAT [you.ERG fish eat.N want.V
'I want you to eat fish.'

The crucial point for our purposes is that in (28) and other imperfective-like constructions illustrated later in this paper, the verb attached to the post-verbal item takes the same nominal form as the embedded verbs that precede the matrix verbs in (30a)(30b), which we consider a sign of syntactic subordination, as opposed to syntactic adjunction/modification: jakôr 'blow.N' and krẽn 'eat.N', respectively.

The second argument in favor of the hypothesis that post-verbal elements such as $n h \tilde{y}$ in (28) function as main verbs that take nominalized clauses as complements, not as syntactic adjuncts or modifiers, is that the lexical verb in nominal form may be fronted for contrast, leaving the progressive-like element stranded, as in (31). Ordinary noun phrases in object position may front and leave a verb stranded along similar lines, so we conclude that post-verbal items such as $n h \tilde{y}$ are structurally similar to verbs, and nominal clauses such as I-djàpêx are structurally similar to ordinary noun phrases that function as syntactic complements.
(31) I-djàpêx nẽ ba $\mathbf{o}=\mathbf{n h} \tilde{y}$.
I-work.N NFUT I $\mathrm{O}=$ sit.V
'It is working that I am (sitting).'

We have shown that post-verbal auxiliaries are syntactic subordinators, not syntactic adjuncts/modifiers. However, an anonymous reviewer suggests that they could be modifiers in a semantic sense. The interpretive effect of negation, however, seems to argue against a semantic modification option for our auxiliaries. As discussed later in Sect. 5.2 in more detail, nhy in (31) is one of the auxiliaries that encode both a progressive meaning and some positional information (i.e., sit). In negative constructions, negation attaches to the auxiliary as in (32), and the resulting interpretation is 
'I am not eating meat (from a sitting position),' and not 'I am eating meat while not sitting.'

(32) Ije mry krẽn o=i-nhỹr kêt.

I.ERG meat eat. $\mathrm{N} \mathrm{O}=\mathrm{I}$-sit.N NEG

'I am not eating meat.' (Not: 'I am eating meat while not sitting.')

Such a reading is easily captured by a logical form where Neg scopes over the progressive-cum-position auxiliary, which in turn scopes over its clausal complement (Neg $>$ Aux $>$ Nominalized Complement), as in our proposed analysis. However, this reading seems unexpected if, as suggested by the reviewer, the auxiliary does not take the nominalized clause as complement, but is a semantic modifier, i.e., a syntactic adjunct of such a clause. More generally, in the absence of negation it is the rightmost element, the post-verbal auxiliary, that is associated with the event-time encoded by left particles in the clause (or null temporal pronouns in the sense of footnote 32).

In contrast to the post-verbal items of interest to this paper, left particles display different properties. For instance, the invariable left particle arỳm 'already' in (29), which we believe instantiates syntactic adjunction/modification, takes no complement. Thus, it co-occurs with a verbal as opposed to a nominal form of the verb both in (29) and (33) (t $\tilde{e}$ ' $g o . V$ '). This particle also displays a position in the clause that is relatively free, as we will also see in later examples, and is constrained by its scopal interpretation and by information structure.
a. Arỳm mã tẽ.
already away go.V
'He left already.'
b. Mã arỳm tẽ.
'He left already.' (with focus on "away”)

Mẽbengokre is strictly head-final, so we may call post-verbal elements 'auxiliaries', and relate left particles to adverbs. To repeat, unlike post-verbal auxiliaries, left particles display no government relations with other heads in the clause, cannot appear as main predicates, and cannot take complements.

One may find cognates with elements of both sets of markers (i.e., adverbs and auxiliaries) in various other languages of the family. While cognates of adverbial left particles may be identified mostly in more closely related languages (see, e.g., Popjes and Popjes 1986 for Timbira), post-verbal elements that in our view encode imperfective aspect may be found with the same function and similar form as far as Kaingang and Xokleng (see Urban 1985; Wiesemann 1986), the most genetically distant of the Jê languages. Urban (1985:174) gives the following description for Xokleng: "A se-

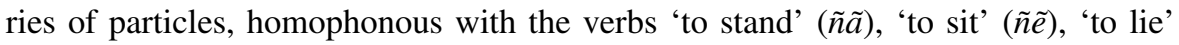


action is viewed as enduring over time." Such parallels in a language that according to Kaufman (1990:47) has been separated from Mẽbengokre by several millennia are remarkable and suggest considerable chronological depth for the grammaticalization of what we consider imperfective auxiliaries in this linguistic family. We also note that, with the exception of Panará, which normally has SVO in main clauses (see Dourado 2001), languages of the Jê family are consistently head final, which provides 
additional typological support for the hypothesis of the origin of aspectual auxiliaries as subordinating heads.

Examples (34)-(35) illustrate some of the post-verbal auxiliaries discussed in this paper, which we divide into two groups for reasons given in Sect. 5.2. English contexts in (34a)-(34b) give an intuitive idea of the semantic contrast between PROSP(ective) and IMM(inent) markers, whose differences we do not further discuss. $^{30}$

(34) Last week...

a. Ije mry krẽn mã.

1ERG meat eat.N PROSP

'I was going to eat meat.'

... but the hunt was not very good.

b. Ije mry krẽn 'ỳr.

1ERG meat eat.N IMM

'I was all ready to eat meat.'

... but our guests finished it before I could get my hands on it.

(35) a. Ba mry krẽn o=nhỹ.

$1 \mathrm{NOM}$ meat eat. $\mathrm{N} \mathrm{O}=$ sit. $\mathrm{V}$

'I am/was eating the meat (sitting down).'

b. Ba mry krẽn $\mathrm{o}=$ dja.

$1 \mathrm{NOM}$ meat eat. $\mathrm{N} \mathrm{O}=$ stand. $\mathrm{V}$

'I am/was eating the meat (standing up).'

c. Maria pry kapêr'yr $\mathrm{o}=$ mõ.

Maria path cross.N $\mathrm{O}=$ go. $\mathrm{V}$

'Maria was crossing the path.'

d. Arỳm nẽ kwỳr nhingrõt $\mathrm{o}=$ nõ.

already NFUT manioc sprout.N O=lie.V

'The manioc is already sprouting.'

The Mẽbengokre auxiliaries in (34)-(35) all convey meanings associated with imperfective categories in many languages, such as those in the Romance and Slavic families in Sect. 3 and Sect. 4 (or less well-studied ones such as Badiaranke in the Niger-Congo subfamily, Cover 2011; also Ancient Greek, Bary 2009). Those in (35), whose properties are discussed in more detail in Sect. 5.2, display the ongoing and event-in-progress readings analyzed in Sect. 3 in the context of Romance and Slavic, and those in (34), less prototypical but nevertheless familiar readings reminiscent of those for planned actions in Romance and Bulgarian, in Sect. 3.3 (see also Cover 2011: Sect. 2.2.4 on Badiaranke Futurates). Thus, we propose that Mẽbengokre postverbal auxiliaries are lexically specified instantiations of imperfective aspect, i.e., lexically marked cases of IMPF. Similarly to Slavic Imperfectives, they encode aspect and not tense, as illustrated in (28) and (36a)-(36b), where post-verbal progressivelike $n h \tilde{y}$ combines with different temporal specifications signaled by the left particles $n \tilde{e}$ and $d j a$.

\footnotetext{
${ }^{30}$ Tense need not be marked in every sentence; examples with overt markers are (28)-(29). In cases without overt markers like (34)-(35), we assume a null pronoun for the topic situation in (4) in Sect. 2.2.
} 
(36) a. Jãkam nẽ ba karinhô jakôr $\mathrm{o}=$ nhỹ. now NFUT 1NOM tobacco blow.N O=sit.V 'I am smoking now.'

b. Kryràm dja ba karinhô jakôr $\mathrm{o}=$ nhỹ. in.the.morning FUT 1NOM tobacco blow.N O=sit.V 'Tomorrow morning I will be smoking.'

In addition, Mẽbengokre auxiliaries give rise to the two types of imperfective-like paradox effects first discussed in Sect. 3.3, when finer distinctions were proposed for the notion of inertia. Thus, (37a) brings to mind events that have already started, while (37b)-(37c) suggest just preparation.

(37) a. Maria pry kapêr'yr o=mõ be kute pry kapêr'yr kêt. Maria path cross. $\mathrm{N} \mathrm{O}=$ go. $\mathrm{V}$ but $3 \mathrm{ERG}$ path cross.N NEG 'Maria was crossing the path but she did not cross the path.'

b. Maria te pry kapêr'yr mã be kute pry kapêr'yr kêt. Maria ERG path cross.N PROSP but 3ERG path cross.N NEG 'Maria was going to cross the path but she did not cross the path.'

c. Maria te pry kapêr'yr 'ỳr be kute pry kapêr'yr kêt. Maria ERG path cross.N IMM but 3ERG path cross.N NEG 'Maria was at the point of crossing the path but she did not cross the path.'

In Sect. 2.2, we proposed that the semantics of Imperfectives has an invariant core, with a universal modal operator quantifying over situations, as in (5) repeated in (38), and variation in the choice of MB accounted for variation in the interpretation of Imperfectives.

(38) Interpretation of IMPF

$\llbracket \mathbf{I M P F} \rrbracket^{\mathrm{c}, \mathrm{g}}=\lambda \mathrm{P}_{<1,<\mathrm{s}, \mathrm{t}>>} \cdot \lambda \mathrm{s} . \forall \mathrm{s}^{\prime}: \mathrm{MB}_{\alpha}(\mathrm{s})\left(\mathrm{s}^{\prime}\right)=1, \exists \mathrm{e}: \mathrm{P}(\mathrm{e})\left(\mathrm{s}^{\prime}\right)=1$.

We then proposed a MB dubbed 'Event-inertia' in (15), arguing that it was generally accessible to IMPF across Romance and Slavic. Extending a similar idea to Mẽbengokre, we now propose that reference to this MB is part of the denotation of the IMPF operator dja 'be standing' in (35b) as formulated in (39), which is thus responsible for the particular progressive-like flavor of this example:

$$
\llbracket \mathbf{d j a}_{\mathbf{I M P F}} \rrbracket^{\mathrm{c}, \mathrm{g}}=\lambda \mathrm{P} \cdot \lambda \mathrm{s} . \forall \mathrm{s}^{\prime} \cdot \mathrm{MB}_{\mathrm{E}-\mathrm{inertia}}(\mathrm{s})\left(\mathrm{s}^{\prime}\right)=1, \exists \mathrm{e}: \mathrm{P}(\mathrm{e})\left(\mathrm{s}^{\prime}\right)=1 .
$$

What is particular to Mẽbengokre, which distinguishes it from Romance and Slavic (or Badiaranke, as reported by Cover 2011), is that the different flavors associated with IMPF are lexicalized, without room for contextual determination of the choice of MB. That is, the different interpretations associated with Imperfectives in the other languages in this paper are attached to specific lexical entries in Mẽbengokre.

In addition to specializing in depicting ongoing events, auxiliaries may specialize for plans or future events, such as the prospective marker $m \tilde{a}$ in (34a). The reading in (34a) is reminiscent of the one in Romance and Bulgarian and Slovenian intentionals in Sect. 3.3, where Imperfectives may allude to plans. We propose that the prospective marker $m \tilde{a}$ in (34a) lexicalizes the Preparatory-inertia MB for events that have been 
set in motion but not yet begun, proposed in (16). On this view, the denotation of the prospective marker in (34a) is given in (40):

(40) $\llbracket$ mã IMPF $\rrbracket^{c, g}=\lambda P . \lambda s . \forall s^{\prime} \cdot M_{P-i n e r t i a}(s)\left(s^{\prime}\right)=1, \exists e: P(e)\left(s^{\prime}\right)=1$.

Given (40), (34a) will be true iff all situations that normally continue plans made in the topic situation, which we assume corresponds to a null pronoun in this instance, are such that they contain an event of me eating meat.

We saw in Sect. 3.1 that generic/habitual readings are typical of Imperfectives in many languages (but see Boneh and Doron 2008). While a full account of generics/habituals in Mẽbengokre must await future research, they do not appear to contradict the approach to IMPF advocated in this paper. Mẽbengokre generic/habitual readings may be tied to plural marking on a nominal form of the verb in independent clauses, as in 'habitual' (41a) and 'generic' (41b), which both bring to mind Ferreira (2005), where habituals relate to plurality. Alternatively, such readings may be tied to plural marking when auxiliaries are present, as in (41c); this sentence may report a repeated activity, and contains auxiliary $i k w \tilde{a}$, the (suppletive) plural form of $n \tilde{o}$ 'lie' in (35d).

(41) a. Krwỳnh ja nẽ kute môp kur. parakeet dem NFUT 3ERG malanga eat.PL.N 'This parakeet eats malanga (often).'

Salanova 2007:(98b)

b. Kukryt kute môp kur.

tapir 3ERG malanga eat.PL.N

'Tapirs eat malanga.'

c. Nãm karinhô jakôr $\mathrm{o}=\mathrm{ikwã.}$

3SG.NFUT tobacco blow.N O= 3.lie.PL

'S/he repeatedly smokes' / 'S/he has been smoking for a long time (lying down).'

For independent reasons, Salanova (2007) argues that (41a) contains a null auxiliary with properties similar to those of the overt auxiliaries in this paper. The issue needs to be studied further, since number in Mẽbengokre also fulfills agreement functions familiar from other languages, as shown in Sect. 5.2, but a preliminary suggestion coherent with our proposals could be that the null auxiliary in (41a) contains IMPF, which accesses the generic/habitual MB proposed in (7).

In our proposal, Mẽbengokre post-verbal auxiliaries share the core semantics of IMPF, but lexicalize the choice of MB. Mẽbengokre differs from the other languages in our study in showing a very rich lexicalization, with distinct forms under a unified morpho-syntactic system for different interpretations. An anonymous reviewer mentions that more familiar languages may express aspect-like notions with a plethora of periphrastic constructions that could also be encoded in MBs, including French être en train de 'to be in the process of' as a progressive, or être sur le point de 'to be on the point of' for an immediate reading, and so on and so forth. However, the lexicalization of Modal Bases we find in Mẽbengokre differs from the situation of periphrastic constructions common in numerous languages in that it resides in postverbal auxiliaries that constitute a closed morpho-syntactic class with parallel structural properties, allow little recursion, and have a wide diffusion in the language 
family. Virtually all sentences in Mẽbengokre discourse that are not part of the main narrative line (and hence employ the perfective form of the verb) require one of the aspectual auxiliaries.

Mẽbengokre provides additional support for our view that the interpretation of IMPF we dub 'Intentional' in Sect. 3.3 should not be determined by a purely pragmatic mechanism of coercion. In Mẽbengokre, purely intentional readings are not available to auxiliaries that encode events in progress, arguing against a view that allows the plans for an event to count as part of the event itself.

Since Mẽbengokre auxiliaries specifically encode intentional readings, the issue of competition does not arise in this language. However, a reviewer suggests the possibility that differences between Mẽbengokre and Romance/Slavic could still be explained pragmatically in terms of semantic specificity, where Mẽbengokre auxiliaries would be more specific than Romance/Slavic imperfectives and less subject to pragmatic manipulation, whereas Romance/Slavic imperfectives would be less specific and thus pragmatically more malleable. In our view, this is not a promising line to take in order to account for the cross-linguistic picture of variation. In Sect. 3.3 we have already seen, for example, that Polish imperfectives lack intentional readings, even though they could be thought to be, in a sense, less specific than Mẽbengokre auxiliaries. (Other instances of this situation could also be illustrated based on our previous discussion.)

In sum, Mẽbengokre auxiliaries are interesting for linguistic theory for at least two reasons: one, they show that MBs may be lexically encoded within a unitary morphosyntactic system and not simply contextually defined, and two, they also suggest that the traditional notion of 'inertia' is not sufficiently fine-grained.

It is well known that lexicalized distinctions between progressives, prospectives, and other imperfective values are common in the languages of the world (cf. Dahl 1985, a.o.) and that progressives are often based on auxiliaries and prepositions indicating location, with the main verb in nominal form (Bybee et al. 1994:129-130, a.o.). What we have shown in this section is that Mẽbengokre offers convincing languageinternal reasons to treat items with such meanings as a unified morpho-syntactic class, and to express their semantic differences as the variation in one component, namely the MB.

\subsection{Two classes of imperfective auxiliaries in Mẽbengokre}

The auxiliaries discussed in Sect. 5.1 lexicalize MBs for the invariant IMPF operator in their denotation, and share a subordinate clause complement, as indicated by the nominal form of their semantic verb. Nevertheless, in this section we argue that they divide into two distinct groups, due to their different morphological makeup and structures they project, coupled to a new semantic characteristic (in addition to the lexical encoding of a MB already discussed in Sect. 5.1).

At least four differences between constructions of types (34) and (35) - partially repeated as (42) and (43) for ease of exposition-support the hypothesis that aspectual auxiliaries in Mẽbengokre divide into two classes.

(42) Ije mry krẽn 'ỳr.

1ERG meat eat.N IMM

'I was all ready to eat meat.' 
(43) Ba mry krẽn o=dja.

$1 \mathrm{NOM}$ meat eat. $\mathrm{N} \mathrm{O}=$ stand. $\mathrm{V}$

'I am/was eating the meat (standing up).'

A first morpho-syntactic difference is that auxiliaries of type (42) share the phonological shape of adpositions, and attach directly to the nominalized verb. By contrast, auxiliaries of type (43) share the phonological shape of positional and motion verbs (and retain their meaning), as we show below. For instance, dja may be glossed by means of English 'be standing', and in its auxiliary function in (43) can be considered a light verb that is linked by the adposition $o$ to the nominal clausal complement, and so on and so forth for other auxiliaries in this class.

A second fundamental morpho-syntactic difference is case. That is, logical subjects in (42) appear in the ergative case (Ije 'I'), while in (43) they appear in the nominative ( $b a$ 'I'). In Mẽbengokre, nominative is assigned or valued in the presence of a finite or verbal form of a verb, so we propose that the auxiliaries in (43) function syntactically as finite (light) verbs that assign or value nominative on an external argument. By contrast, the auxiliaries in class (42) that resemble adpositions do not assign/value case other than absolutive to/on the nominal subordinated clause containing the lexical verb, with ergative marking on the subject originating within this nominal clause complement (for case in Mẽbengokre, see Salanova 2007, 2008; for case with auxiliaries, see Salanova et al. 2012). The adposition $o$ found with auxiliaries of type (43) licenses the subordinated nominal clause by assigning/valuing absolutive case to/on it.

A third difference is number. The auxiliaries in (43) have suppletive plural forms obligatorily selected when the subject is plural, as illustrated in (44) with $k u$ ' $\hat{e}$ - the plural form of $d j a$ 'stand' in (43). ${ }^{31}$ (For number agreement between auxiliaries and subjects in Jê languages, see Urban 1985; Wiesemann 1972; Salanova 2014; a.o.)

(44) Mẽbêngôkre nẽ mẽ kabẽn $\mathrm{o}=\mathrm{ku}$ 'ê.

Mẽbengokre NFUT PL speak.N O=stand.V.PL

'The Mẽbengokre are speaking.'

A number relation similar to the one in (44) is not found with auxiliaries of type (42). For instance, Imminent ' $y r r$ in (42) is invariable.

The most relevant difference for our proposals on IMPF is semantic. Namely, there is a thematic-like relation between nominative subjects and auxiliaries in $(35)=(43)$ that does not exist between ergative subjects and auxiliaries in $(34)=(42)$ : the position or motion encoded in the auxiliaries in (35) is the one in which the subject is performing the action. Thus, we have different progressives based on whether the subject is sitting, (35a), standing, (35b), moving, (35c), lying, (35d), but a similar contrast is not found in (34).

In view of such differences, we conclude that the auxiliaries in $(35)=(43)$ establish morpho-syntactic (case) and semantic (thematic role) relations with the logical subject of the sentence, while those in $(34)=(42)$ do not establish relations with such

\footnotetext{
${ }^{31}$ Recall that with singular logical subjects, such 'verbal plurals' are also interpretable as generics or habituals as noted in Sect. 5.1 when we discussed (41a)-(41b).
} 
a subject. To primarily capture semantic relations, we propose to treat auxiliaries in group (35) as 'control' predicates, and those in (34) as 'raising' predicates. This is illustrated in (45a) and (45b), setting aside tense. (Index ' $i$ ' in (45b) is an 'abstraction index' à la Heim and Kratzer 1998.) We use 'raising' and 'control' as descriptive labels to encode the division between the two kinds of auxiliaries, without espousing a precise syntactic analysis, a topic that is not crucial for the proposals in this paper, and falls beyond its scope. Thus, prospective $m \tilde{a}$ in (45a) could also be viewed as an impersonal predicate that takes just a nominal argument as complement, without projecting a specifier to which the subject of the lower nominalized clause raises syntactically. In the same vein, we could also think of progressive $n h \tilde{y}$ in (45b) as a light verb whose derived subject hyper-raises (cf. Hornstein 1999 and later work) from the embedded clause into a thematic position in the matrix clause (i.e., the so-called movement analysis of control), amongst other syntactic options, which we leave to future research.

\section{a. Raising}

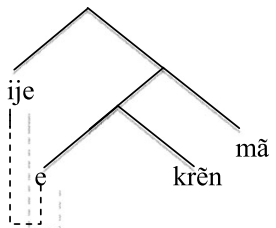

b. Control

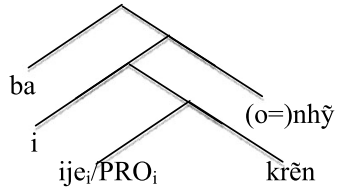

What is important for our purposes is the existence of a distinct class of 'control' auxiliaries in Mẽbengokre, a claim we justify before we turn to their semantics.

The auxiliaries that fall in the control class are, as we said above, chosen from a variety of stative positional verbs, which display similar selectional restrictions for subjects, whether used in locative/existential constructions, or in our progressive constructions. Let us illustrate the parallelism, which we see as support for our analysis of control auxiliaries. Mẽbengokre exhibits positional-like verbs in locative or existential constructions whose choice depends on the shape of inanimate subjects, as shown in (46a)-(46b). That is, elongated objects in horizontal position require the positional verb nõ, as in (46a), while objects that are soft and drooping normally require positional wajêt, as in (46b), among other options left unmentioned for lack of space.

(46) a. Pur kam ne kwỳr nõ.

Garden in NFUT manioc lie.V

'The manioc is in the garden.'

b. Pijê 'ã ne mokà wajêt.

Beam on NFUT rucksack hang.V

'The rucksack is on the beam.'

When such positional verbs are used as light predicates in the progressive option, selectional restrictions are the same, as (47a)-(47b) illustrates. Thus, kwỳr 'manioc' in (47a), which repeats (35d), combines with progressive nõ 'lie', while mokà 'rucksack' in (47b) co-occurs with progressive wajêt 'hang', which is another auxiliary in 
the control class that may be used as a copula in existential and locative constructions.

(47) a. Arỳm nẽ kwỳr nhingrõt $\mathrm{o}=$ nõ.

already NFUT manioc sprout.N $\mathrm{O}=$ lie. $\mathrm{V}$

'The manioc is already sprouting.'

b. Arỳm ne mokà ngo $\mathrm{o}=$ wajêt. already NFUT rucksack get.wet $\mathrm{O}=$ hang. $\mathrm{V}$

'The rucksack is getting wet already.'

Thus, while the semantic content of positional verbs in an auxiliary function in (47) and elsewhere is primarily aspectual (i.e., they are grammaticalized progressives), a semantic relation with the grammatical subject is still required. In addition, some inanimate subjects are incompatible with specific positional auxiliaries; so while the rain may fall by 'standing', as with dja in (48a), it cannot fall using auxiliary nõ 'lie', which would be deviant as in (48b), and so on.

$$
\begin{aligned}
& \text { a. } \mathrm{Na} \text { rwỳk } \quad \mathrm{O}=\text { dja. } \\
& \text { rain come.down. } \mathrm{N}=\text { stand. } \mathrm{V} \\
& \text { 'It is raining.' } \\
& \text { b. \#Na rwỳk } \mathrm{O}=\text { nõ. } \\
& \text { rain come.down. } \mathrm{N}=\text { =lie. } \mathrm{V}
\end{aligned}
$$

The relation of human / animate subjects with auxiliaries in the control class seems more indirect, but appears to depend on the activity carried out by the nominative subject. Natural answers to the question in (49) trigger different control auxiliaries on the basis of depicted activities. Thus, an ongoing combing activity combines naturally with progressive dja 'be standing' in (49a), an ongoing reading activity triggers auxiliary $n h \tilde{y}$ 'be sitting' in (49b), and an ongoing sleeping activity is better described via auxiliary $n \tilde{o}$ 'be lying' in (49c).

(49) Question: What is X doing?

a. ... Nãm ami-kakrwỳnh $\mathrm{o}=$ dja.

s/he self-comb.N $\mathrm{O}=$ stand. $\mathrm{V}$

'S/he is combing himself (standing up).'

b. ... Nãm pi' ôk jarẽnh $\mathrm{o}=$ nhỹ.

s/he paper tell.N $\mathrm{O}=$ sit.V

'S/he is reading (sitting down).'

c. ... Nãm õt $\quad \mathrm{o}=$ nõ.

s/he 3.sleep.N O=lie.V

'S/he is sleeping (lying down).'

Control auxiliaries thus select for the default position an animate subject occupies to perform a particular action. When the default auxiliary is not chosen, the sentence is grammatical, but the physical position of the subject becomes salient. To illustrate, the English translations in (50) intend to capture some inferences made by one of our main consultants when interpreting unexpected auxiliaries. Thus, when jarẽnh 'read' combines with dja 'be standing' in (50a), the consultant infers that the reader is in 
front of an audience. When $\tilde{o} t$ 'sleep' combines with wajêt 'be hanging' in (50b), the informant deduces sleeping in a hammock (i.e., a hanging position).

(50) Question: What is X doing?

a. ... Nãm pi'ôk jarẽnh $\mathrm{o}=\mathrm{dja}$.

s/he paper tell.N $\mathrm{O}=$ stand.V

' $\mathrm{S} / \mathrm{he}$ is reading out loud, in front of his/her students.'

b. ... Nãm õt $\mathrm{O}=$ wajêt.

s/he 3.sleep. $\mathrm{N} \mathrm{O}=$ hang.V

'S/he is sleeping in a hammock.'

In sum, we conclude that relations such as case marking, number agreement, and selectional restrictions affecting subjects with respect to only one class of auxiliaries support the hypothesis that such auxiliaries behave like control predicates: they participate in a complex structure where they function as external-argument-selecting predicates that take a nominalized clause with the main verb as their complement.

The class of raising auxiliaries in Mẽbengokre resembles imperfective categories in better-known languages, which do not impose a thematic restriction on their subjects, so the semantics already discussed in Sect. 5.1 fits them without modification. However, to capture the additional positional meaning of control auxiliaries, we need to modify the semantics for IMPF in (38). Consider (35a), repeated as (51):

(51) Ba mry krẽn o=nhỹ.

$1 \mathrm{NOM}$ meat eat. $\mathrm{N} \mathrm{O}=$ sit. $\mathrm{V}$

'I am/was eating the meat (sitting down).'

As a control auxiliary, aspectual $n h \tilde{y}$ 'be sitting' takes the nominative subject as argument, imposing restrictions on it as part of the truth-conditions of the sentence. Thus, we propose to adapt slightly the semantics of IMPF in (38) to allow this operator to take an entity as an argument, so as to combine with a subject in syntax, as in (52).

$$
\begin{aligned}
& \llbracket \mathbf{n h} \tilde{\mathbf{y}} \rrbracket^{\mathrm{c}, \mathrm{g}}=\lambda \mathrm{P} \cdot \lambda \mathrm{x} \cdot \lambda \mathrm{s} . \forall \mathrm{s}^{\prime} \cdot \mathrm{MB}_{\mathrm{E}-\text { inertia }}(\mathrm{s})\left(\mathrm{s}^{\prime}\right)=1, \exists \mathrm{e}: \mathrm{P}(\mathrm{x})(\mathrm{e})\left(\mathrm{s}^{\prime}\right)=1 \text { and sit- } \\
& \operatorname{ting}(\mathrm{x}, \mathrm{s}) .
\end{aligned}
$$

According to (52), Imperfectives auxiliary $n h \tilde{y}$ in (51) combines with a property of individuals and events (P) (type $<\mathrm{e},<\mathrm{l},<\mathrm{s}, \mathrm{t}>>>$ ) and an individual (x), quantifying over events and introducing their agent in a certain position. The result is a proposition true of a situation $\mathrm{s}$ iff $\mathrm{x}$ is sitting down in $\mathrm{s}$ and, in all situations $\mathrm{s}^{\prime}$ that are Event-inertia situations for $\mathrm{s}$, there exists a P-event with $\mathrm{x}$ as agent. (Recall that Event-inertia situations s' for $s$ are those where all the events that have actually started in s continue in $s^{\prime}$ as they would if there were no interruptions.) As an aspect marker with its own logical subject, nhỹ imposes restrictions, via control, on the subject of the embedded clause.

Putting things together, the interpretation of (51) is composed as follows: (53) presents the LF of (51) using PRO to indicate the subject of the main semantic verb, (54a)-(54c) shows the denotation of various parts of the structure, and (55) shows the truth-conditions of (51). (We assume a past topic situation, and an index abstracting over PRO.) 
(53) $\left[\mathrm{s}_{\mathrm{j}}\left[\mathrm{ba} \quad\left[\mathrm{i}\left[\mathrm{PRO}_{\mathrm{i}}\right.\right.\right.\right.$ tep krẽn $\rrbracket \mathrm{o}=\mathrm{nhỹ} \rrbracket$ $1 \mathrm{NOM} \quad$ fish eat.N O sit.V [where $\mathrm{s}_{\mathrm{j}}$ is the past topic pronoun] 'I was eating fish (sitting down).'

(54) a. $\mathbb{i} \mathbf{i} \mathbf{P R O}_{\mathbf{i}}$ tep krẽn $\mathbb{\rrbracket}^{c, g}=\lambda x . \lambda$ e. $\lambda$ s.e is an event of $\mathrm{x}$ eating the fish in $\mathrm{s}$

b. $\quad\left[\mathbf{b a} \mathbb{\|}^{\mathrm{c}, \mathrm{g}}=\right.$ the speaker in $\mathrm{c}$

c. $\left[\mathbf{s}_{\mathbf{j}} \mathbb{\rrbracket}^{\mathrm{c}, \mathrm{g}}=\mathrm{s}_{\text {topic }}\right.$.

(55) $\llbracket\left[s_{\mathbf{j}}\right.$ ba i PRO $\mathbf{~}_{\mathbf{i}}$ tep krẽn o $=$ nhỹ $\mathbb{1}^{c, g}=1$ iff the speaker in $\mathrm{c}$ is sitting down in $\mathrm{s}_{\text {topic }}$ and $\forall \mathrm{s}^{\prime}: \mathrm{MB}_{\mathrm{E}-\text { inertia }}\left(\mathrm{s}_{\text {topic }}\right)\left(\mathrm{s}^{\prime}\right)=1$, $\exists \mathrm{e}: \mathrm{e}$ is an event of the speaker eating the fish in $\mathrm{s}^{\prime}$.

According to the above proposal, (51) will be true iff the speaker is sitting down in the topic situation, and all situations that normally continue the events that have begun in the topic situation include events of the speaker eating the fish. ${ }^{32}$

In this section we have provided a semantics for Mẽbengokre aspectual auxiliaries within the general framework for IMPF in Sect. 2.2, and concluded that they lexically encode different MBs. The claim that Imperfective auxiliaries in Mẽbengokre lexically encode different MBs unfolds into two related but distinct ideas: (1) variation in imperfective meaning may in many cases be reduced to variation in the content of MBs accessible to the IMPF operator, and (2) certain languages may have an 'enriched' repertoire of IMPF auxiliaries that lexicalize distinct MBs. This is the case of Mẽbengokre, which therefore contributes to our program to minimize the various roles often assigned to pragmatics in the literature on imperfectives and their read-

\footnotetext{
${ }^{32} \mathrm{We}$ assume that proclitic $o=$ is semantically vacuous, and the positional verb with IMPF carries aspect. Mõ 'moving slowly' is the only auxiliary that displays both a control and a raising version, and can be used to support our assumption. Consider (i)-(ii).
}

(i) a. Kikre mã i-djàr mõ.

House in 1-enter. $\mathrm{N}$ go. $\mathrm{V}$

'I am entering the house.'

b. I-nhõ krit nẽ tyk mõ.

1-POSS pet NFUT die.N go.V

'My pet is dying.'

(ii) a. Ba a-mã i-kabẽn $\mathrm{o}=$ mõ.

1NOM 2-DAT 1-speak $\mathrm{O}=$ go.V

'I am talking to you.'

b. Ba karinhô jakôr $\mathrm{o}=\mathrm{mõ}$.

1NOM tobacco blow.N O=go. $\mathrm{V}$

'I am smoking.'

$O=$ is not present if the main verb is unaccusative, (i), and present if it is unergative or transitive (ii), but progressive meaning is present in all cases. Thus, $o=$ marks that the subject is an agent / causer, rather than an involuntary undergoer, not aspect. This is reminiscent of the contrast between the two Korean imperfective markers: - ko iss with unergatives and transitives, and - a iss with unaccusatives (Lee 2008). For reasons of space, we do not examine $m \tilde{o}$, and simply assume that $o=m \tilde{o}$ behaves like control auxiliaries, while $m \tilde{o}$ behaves like raising auxiliaries. Further research is needed to determine to what extent $o=m \tilde{o}$ imposes (and $m \tilde{o}$ does not) restrictions on the subject. 
ings, since it shows conclusively that choice of MB cannot always be determined by pragmatics.

\section{IMPF interactions and variation}

In this section, we examine a last source of cross-linguistic variation, which involves the compositional interaction of IMPF with other modal operators in the clause. Such modal interactions serve to illustrate that the shared skeleton we propose for IMPF combined with different MBs available to this operator in some languages but not others can accommodate considerable differences between both Romance and Slavic and within the Slavic family itself. In addition, it is also important that such interactions provide additional support for our proposal that IMPF is not devoid of semantic content, which, as we pointed out in the conclusion to Sect. 4, favors the proposals in this paper when compared to approaches where imperfectivity is semantically 'empty', and readings derive from phonologically null operators in the clause. In each of the cases examined in this section, we see interactions between IMPFs and other operators in the language that are predictable given our proposal for IMPF and the interpretation of the relevant other operators.

To support that IMPF makes its own semantic contribution while not necessarily accessing the same MBs in all languages, in Sect. 6.1 we examine the Bulgarian Renarrated Mood (RM), with a dominating Epistemic Modal interacting with IMPF, and in Sect. 6.2, we consider Slavic Involuntary States (ISs), where a dominating Circumstantial may interact with IMPF. In such interactions, IMPF may freely contribute all the available readings in a given language (i.e., access all available MBs in the language in question), as in the Bulgarian RM, and West and East Slavic ISs. In simple terms, imperfective versions of the RM depict reported events as ongoing, intentional, and so on, in parallel to Indicative Imperfectives in Sect. 3. Thus, when interacting with an Epistemic, IMPF accesses all the available MBs in Bulgarian, including the one behind Indicative intentionals. Likewise, West and East Slavic imperfective ISs with dative subjects depict events as ongoing, habitual, and so on, similar to West and East Slavic Imperfectives with nominative subjects in Sect. 3, but, crucially, they lack an intentional reading because the Preparatory-inertia MB in Sect. 3.3 is not available to IMPF in this group. Thus, IMPF freely interacts with an Evidential in the first case, and a Circumstantial in the second, contributing readings independently available in the language in both instances. Alternatively, IMPF may interact in a more specialized manner. In Sect. 6.2 we argue that in desiderative ISs in South Slavic, the Circumstantial exclusively interacts with an Intentional IMPF; here, too, IMPF contributes its own meaning, albeit a more specialized one. This situation leads to a semantic contrast with West and East Slavic, where the MB behind Intentionals is not available to IMPF, and thus Involuntary States do not have a desiderative reading in this group.

\subsection{IMPF and the Renarrated Mood in Bulgarian}

Bulgarian has a Renarrated Mood (RM) with a dedicated morphology for indirect evidence illustrated in (56a), which Izvorski (1997) labels 'Perfect of Evidentiality.' 
(56) a. Ivan izpil vsičkoto vino včera.

(Izvorski 1997)

Ivan drunk.RM all.the wine yesterday

'Ivan apparently drank all the wine yesterday.'

b. Ivan e izpil vsičkoto vino včera.

'Ivan has drunk all the wine yesterday.'

The bolded RM form in (56a) shares a past participle with the Indicative Perfect in (56b), but lacks an auxiliary in the third person. RM forms contain a past morphological component, and exhibit a full paradigm of (often periphrastic) tenses (Scatton 1983; Rivero 2005). Thus, they can allude to past, present, and future, in parallel to tenses of the Indicative Mood, which according to Izvorski are understood as based on direct evidence justifying belief. To illustrate, the Perfect of the RM in (57a) contrasts with the Indicative Perfect in (57b), and so on and so forth.
a. Az săm
bil čel
Anna Karenina.
I be.1Sg.Pres be.RM read.PART Anna Karenina 'I have apparently read Anna Karenina.'
b. Az săm čel Anna Karenina
I be.1Sg.Pres read.PART Anna Karenina.
'I have read Anna Karenina.'

(Izvorski 1997)

Izvorski offers a modal analysis of RM within a Kratzer-style framework, whose basic tenets we adopt. She proposes that RM contains an evidentiality operator Ev: a universal epistemic modal with a presupposition about indirect evidence, interpreted as 'It is said that p,' or 'I infer that p. ${ }^{33}$ What is relevant for our proposals is that, besides indirect evidence, RM constructions must also encode perfectivity/imperfectivity in the participle. As we show next, Imperfective RM forms mimic readings of Bulgarian Imperfectives in the Indicative Mood. To our knowledge, the workings of imperfectivity in the RM have not attracted particular theoretical attention, but they strongly support our contention that IMPF is not empty of content, and contributes independent readings. Imperfectivity in the RM also supports our view that the Modal Base underlying Intentionals is formally encoded in Bulgarian.

To understand the functions of IMPF in RM forms, let us begin by considering (58).

(58) Kogato mayka i došla / *doydela v stayata i, Mary

When mother her come.RM.PF /*IMPF in room her Mary

govorela / *govorila s priyatelya si.

speak.RM.IMPF/ *PF with boyfriend.def her.

'Apparently, when her mother came into her room, Mary was talking to her boyfriend.'

Sentence (58), with a Perfective participle došla '(apparently) came' in the whenclause, displays an Imperfective participle govorela '(apparently) was speaking' with

\footnotetext{
${ }^{33}$ Quoting Izvorski (1997:226), "Sentences of the form EVp [...] result in the interpretation that $p$ is possible, very likely, or necessary relative to the knowledge state of the speaker." Interested readers are referred to her work for the semantic implementation.
} 
an ongoing reading in the main clause (the opposite morphology is not appropriate). Thus, this RM construction shares the reading of ongoing Indicative Imperfectives in Sect. 3.2. RM (59), reminiscent of traditional imperfective-paradox patterns, has an Imperfective participle (pečelel 'apparently was winning') with a reading related to the Event-inertia MB in Sect. 3.3.

(59) Saxmatistăt pečelel/*pečelil igrata kogato bil udaren po Chess.player.def win.RM.IMPF/*PF game.the when Aux.RM hit on glavata i igrata bila prekăsnata. head.def and game.def Aux.RM interrupted 'Apparently, the chess player was winning the game, when he was hit in the head and the game was interrupted.'

A generic-like Imperfective participle živeeli 'apparently lived' in (60), in a context where perfective živeli is not appropriate (habituals are parallel), resembles Indicative Imperfectives in Sect. 3.1 with the Generic MB shared by Slavic and Romance.

(60) Dinozavrite *živeli / živeeli v džunglata. dinosaurs live.RM.PF /IMPF in jungle.def 'Apparently, dinosaurs lived in the jungle.'

We saw in Sect. 3.3 that Bulgarian and Romance share Intentional Imperfectives with a Preparatory-inertia MB absent in East and West Slavic. An Intentional RM is in (61). Imperfectives poseštavali 'apparently they were visiting' transmits the information that the trip did not take place, so identifies a past plan. If Perfective posetil 'apparently they visited' had instead been used, it would indicate that the visit took place, in conflict with Perfective otkazali 'they apparently canceled.'

(61) Sledvaštata sedmica poseštavali Pariž, no imalo stački i

Next.def week visit.RM.IMPF Paris but there.was strikes and otkazali pătuvaneto.

deny.RM.PF trip.def

'Apparently, next week they were visiting Paris, but there were strikes, and they canceled the trip.'

The above sentences illustrate that imperfectives play their usual roles in the RM, with readings closely tracked by morphology. In (61), for instance, (secondary) Imperfective- $v a$ - signals IMPF, and the Participle signals the Ev-operator proposed by Izvorski.

In sum, all the readings of IMPF available in Bulgarian Indicative Imperfects in Sect. 3 are also found in Imperfective versions of the RM, including the Intentional type based on the Preparatory-inertia MB subject to micro-variation in Slavic. We have followed Izvorski in adopting the hypothesis that RM contains an Epistemic operator. On such a view, the above RM patterns demonstrate that when IMPF composes with this c-commanding Ev in the doubly modalized structure $\left[\mathrm{EV}_{\mathrm{op}}\left[\mathrm{IMPF}_{\mathrm{op}}\right]\right]$, it accesses the different MBs proposed for Bulgarian in Sect. 3, which allows us to see the compositional contribution of each MB. This clearly demonstrates that (a) IMPF is not semantically 'unmarked', (b) IMPF does not derive its reading from other operators but contributes its own interpretations, and (c) such interpretations under the 
scope of an epistemic operator cannot be attributed to extra-linguistic context, nor to pragmatic principles of a conversational type. In the RM, IMPF may access the MB we dub Preparatory-inertia, which provides further support for our contention that this MB is formally encoded in the grammar of Bulgarian.

Before concluding with RM, we recall Romance Narrative Imperfectives in Sect. 4.2, as in Spanish (62). Romance Narratives seem relevant in the discussion of the Bulgarian RM, given that they appear similar to some RM patterns, as the comparison of (62) with (63) illustrates, both glossed by 'At eight, the robbers entered the bank, discussed with a clerk, and moved towards the main window.'

(62) A las ocho, los ladrones entraban en el banco, discutían con un

At the eight, the robbers entered (Impf) in the bank, argued (Impf) with an

empleado, y se dirigían a la ventanilla principal.

employee, and Refl directed (Impf) to the window main

(63) V osem časa kradcite vlezli v bankata, govorili

At eight hours robbers entered (RM.PF) in bank.the, spoke (RM.PF)

s edin ot služitelite, posle se otpravili kăm glavnoto giše.

with one of employees.the, after refl moved (RM.PF) towards main.the window

The sequence of bolded Narrative Imperfectives in (62) and RM verbs in (63) are both suitable to depict past complete events that advance the narration. We noted in Sect. 4.2 that depicting culminating events that advance the narration defines Romance Narratives, so we may wonder if this is because they also contain an Evidential similar to what we find in RM. ${ }^{34}$ As we have noted earlier, however, in our view Narrative Imperfectives and the RM are only superficially similar, and have distinct underlying semantics. In Sect. 4.2 we proposed an analysis of Romance Narrative Imperfectives that appeals to a specific MB for IMPF. Imperfective RM forms, on the other hand, consist of Ev and IMPF, which may access several MBs and contribute independent readings available in Bulgarian. If Romance Narratives also contained an epistemic operator scoping over IMPF like Bulgarian RMs, they would also display a range of readings for IMPF, contrary to fact. As stressed in the literature, Romance Narratives lack what are considered bona fide imperfective readings in traditional grammars, obtaining only the complete-event reading we discussed in detail in Sect. 4.2. A second major difference is that all the RM forms in (63) are perfective, not imperfective, so the function of advancing the narrative does not fall on imperfectives in the RM (or elsewhere in the Slavic family if our proposals are correct).

In sum, the functions of imperfectivity in Romance Narratives and the Bulgarian RM are not the same. Imperfectivity is parallel in RM and non-RM contexts in Bulgarian, but in Romance Narratives, it leads to a complete-event interpretation not available in other contexts as discussed in Sect. 4.2. We argue that this contrast arises because in the RM the IMPF operator is interpreted in the scope of the evidential modal (Ev) and has access to a wide range of MBs (but not the Narrative MB), while

\footnotetext{
${ }^{34}$ Reyes (1990) suggests a connection between Narrative Imperfectives in Spanish and the Bulgarian RM. For Labelle (2003), French Narrative Imperfectives contain an operator with a purely pragmatic effect above imperfectivity.
} 
in Romance Narratives IMPF is the only operator (this is not a case of double modality), and achieves a particular interpretation via a specialized MB.

In conclusion, the RM consists in both an active Epistemic Operator and an active IMPF (or PF), while Romance Narratives contain only one layer of modality (IMPF). Differences between the two constructions are closely tracked by morphology. On the one hand, RM forms are marked with doubly faceted morphology: a participle for the epistemic operator, and imperfective (or perfective) morphology for IMPF (or $\mathrm{PF}$ ), each playing a different semantic role. On the other hand, Romance Narratives are marked by a simple imperfective morphology, without evidential morphology. ${ }^{35}$

\subsection{Involuntary States and IMPF}

A last case of variation for IMPF in a situation of double modality we consider involves Involuntary States (ISs), with dative subjects, default Vs, and reflexives, as in (64)-(65). Involuntary states serve to further demonstrate that IMPF may access the Preparatory Modal Base in Sect. 3.3 in South Slavic, but such is not the case in West and East Slavic.

(64) Janezu se je plesalo vsem na očeh. Slovenian

J.Dat Refl Aux.3Sg danced.Neut to.everybody on eyes=in plain view

'John felt like dancing in plain view.'

(adapted from Rivero and Sheppard 2008)

(65) Jankowi tańczyło się dobrze.

J.Dat danced.Neut Refl well

'(Somehow), John danced with pleasure.'

ISs are found in all Slavic languages, but with different semantics and truth conditions. In South Slavic as in (64), imperfective ISs allude to an urge of the dative subject not actualized in the 'real' world (no actual dancing). In East and West Slavic, as in Polish (65), they involve an 'actualized' event depicted by the verb (actual dancing). ${ }^{36}$ Adopting proposals in Rivero and Arregui (2012), to which we refer the interested reader, we attribute the above semantic variation to the contrasting interactions

\footnotetext{
${ }^{35}$ Bulgarian Indicative Imperfects do not display characteristics we dub 'Narrative' in Sect. 4.2 (i.e., IMPF does not access the Narrative MB, which is so far specific to Romance), so (i) contains an Indicative Imperfect, but does not have the complete-event reading of its Romance morphological equivalent also in the Indicative Imperfect in (22d). In the RM, this type of meaning is expressed by a perfective participle, as in (ii).
}

*Prez 1492 godina Xristofor Kolumb otkrivaše Amerika.

*In 1492 year Christopher Columbus discovered (Impf) America

(ii) 1492 godina Xristofor Kolumb otkril Amerika.

[Apparently], in 1492 year Christopher Columbus discovered.RM.PF America

We do not explore the contrast between Romance and Bulgarian Indicative Imperfects, but it seems to add support to the semantic analysis of Romance Narratives in Sect. 4.2, against a purely pragmatic treatment. Under a pragmatic analysis of Narratives, parallel conversational mechanisms should be available to Bulgarian Indicative Imperfects in (i), contrary to fact.

${ }^{36}$ As discussed by Rivero and Arregui (2012), Russian ISs pattern with those in Polish, in so far as they also involve the actualized event that is depicted by their verb; this leads them to the conclusion that Russian is 
of IMPF coupled to available MBs with a dominating Circumstantial Modal. Rivero and Arregui (2012) argue that the two semantic types of ISs illustrated in (64)-(65) are doubly modalized structures sharing the (oversimplified) structure in (66): a null circumstantial modal (CM), signaled by dative morphology on the logical subject, dominates an IMPF operator signaled by an imperfective verb. The core of the proposal is that CM and IMPF interact in different ways in South Slavic on the one hand, and in East and West Slavic on the other, because this operator does not access the same variety of MBs in the two groups. This results in the different truth conditions of (64) labeled 'desiderative' and (65) labeled 'factual'.

(66) $[\mathrm{CM}[$ Tense [Viewpoint IMPF [ V]]]]

On the one hand, in South Slavic, CM selects for an Intentional IMPF with the Preparatory-inertia MB in Sect. 3.3. One consequence of the specialization of CM is that ISs must be imperfective in this group. Desiderative semantics (i.e., an uncontrollable and non-actualized urge) results compositionally from the denotation of $\mathrm{CM}$ and the semantics for the Intentional IMPF proposed in Sect. 3.3 based on the Preparatory-inertia MB. On the other hand, the actualized reading of ISs in West and East Slavic (i.e., an agent acting without control over his/her action) is due to two factors. The first is that in this group, CM does not impose particular selectional requirements on a Viewpoint Operator. As a consequence, ISs may be imperfective, (65), or perfective, (67), and both allude to actualized actions (actual dancing and actual writing).

\section{(67) Napisało}

mi się własne imię.

Po

Wrote.neu.PF I.Dat REFL own name

'I wrote my own name (by accident).'

(Rivero et al. 2010)

The second factor resides in the nature of the Modal Bases accessible to IMPF in (66). We argued in Sect. 3.3 that Intentional Imperfectives are unavailable in East and West Slavic, i.e., IMPF in this group cannot access the Preparatory-inertia MB, so when CM composes with IMPF in this group, available options include ongoing readings (an Ongoing MB), as in (65), or generic /habitual readings as in (68) (a Generic MB), but not intentional readings, given the unavailability of a Preparatoryinertia MB. This MB is instrumental in the desiderative meaning of South Slavic ISs. Thus, East and West Slavic ISs cannot receive a desiderative interpretation, but only one with 'actualization', which may depend on the Ongoing or the Generic MB.

$$
\begin{aligned}
& \text { Naskol'ko slašče žilos' } \quad \text { putešestvennikam XIX veka! } \\
& \text { How.much sweetly lived.Impf.Neu.Refl travellers.Dat } 19^{\text {th }} \text { century } \\
& \text { 'How much better travellers lived in the } 19^{\text {th }} \text { century!' }
\end{aligned}
$$$$
\mathrm{Ru}
$$

In sum, South Slavic ISs are 'desiderative' and East and West Slavic ISs are 'actualized', so the two types differ in truth conditions, and such a variation derives from interactions of IMPF in combination with its MBs with a Circumstantial in a

one of the Slavic languages without Intentionals, i.e., the Preparatory-Inertia MB is not available to IMPF. In footnote 21 we gave a different argument that places Russian amongst languages without Intentionals. 
doubly modalized structure. More precisely, in South Slavic ISs, IMPF accesses a Preparatory- inertia MB unavailable in West Slavic and East Slavic. By contrast, in West and East Slavic ISs, IMPF accesses other MBs available in its group, including the one we call Event-inertia in Sect. 3.3.

To conclude, in this section we examined RM constructions in Bulgarian and ISs in several Slavic languages, and argued that both demonstrate that IMPF contributes its invariant semantic core in each case, and that variation depends on the MBs IMPF may access in such constructions. In particular, Involuntary States divide into two semantic types because Preparatory-inertia is not available to IMPF in East and West Slavic.

\section{Conclusions}

An important goal of this paper has been to argue for the need of a cross-linguistic perspective framed within a unified semantic model in order to better understand the general characteristics of imperfectivity together with the considerable existing variation in the interpretation of imperfectives observed when comparing languages both within a family and across families.

Bringing together information from diverse languages and different morphosyntactic systems, we have shown that a modal analysis of IMPF can account both for the temporal dimensions usually linked to imperfectivity, as in the traditional inclusion view that locates reference time within the event time, and for less discussed interpretations, including Intentionals in Romance and some Slavic languages, Factuals in some Slavic languages, and Narratives in Romance, thus tying properties of imperfectives sometimes considered as modal to their widely known temporal properties.

We have argued that languages may vary along a number of lines, with such variation affecting the precise interpretation of imperfectives that nevertheless share an invariant semantic architecture. That is, languages may be more or less permissive regarding the range of options available to contextually or linguistically determined modal bases for IMPF, they may allow for a more or less rich lexical specification of certain modal bases, and they may also allow for different types of morphosyntactically encoded interactions between IMPF and other operators in the clause. Within such a variation, our aim has been to develop a unified perspective that allows us to account for the observed contrasts, which can be considerable, while also capturing a common semantic core that we have argued all imperfectives share.

Imperfectives have often been studied in great detail on a language-particular basis from numerous descriptive and theoretical points of view, but general comparative perspectives on imperfectivity are still relatively rare. We argue, however, that a crosslinguistic perspective is crucial in order to properly understand the intrinsic semantic contribution of imperfectivity, and to distinguish such a contribution, which we argue is invariant, from that which is part of language-specific realizations. Adopting an ontology based on situation semantics, where distinctions between modal and temporal categories are blurred, we have argued for a formal analysis of imperfectivity consisting of a core quantificational semantics for an imperfective operator IMPF 
shared across languages, with variation depending on different \{linguistically encoded/grammaticized \} restrictions on the domain of quantification. More precisely, we have maintained that modality is at the heart of all imperfectives, and that the wide range of variation in their interpretation observed both when comparing closely related languages (e.g. within the Slavic family) or languages that are unrelated (e.g. Mẽbengokre vs. Slavic and Romance) can be accounted for by means of restrictions on IMPF as a modal quantifier that may be linguistically encoded or grammaticized in different ways depending on the language.

The modal treatment of IMPF raises the important question of the general properties of modality at the aspectual level, and the kinds of restrictions on the domain of quantification (i.e., modal bases) that may differentiate this type of modality from more familiar and traditional kinds, such as the epistemic variety, the deontic variety, and so on and so forth. We do not have a fully developed answer to this question, but it is interesting to note that all the modal interpretations observed for IMPF are very much 'event-centered'. In the case of imperfectives, we seem to be in general interested in the distribution of events in relation to a topic situation (i.e., within subparts of the topic situation, in situations leading up to the topic situation, or in continuations of the topic situation). So even though we have framed our proposal within a modal framework, the traditional questions of the aspectual literature regarding the relation between events and topic situations remain very much central in the discussion. We have speculated in passing that the relatively low syntactic position of IMPF below Tense, in contrast with the higher location typically attributed to other modals, may be partially responsible for the event-centered nature of the accessibility relations associated with IMPF. More conclusive answers to the important question about the cross-linguistic typology of accessibility relations/modal bases for IMPF raised by our proposals, however, will require further investigations into the modal nature of aspect (including deontic flavors of perfectivity in the Slavic family), and must remain for future research.

As we have seen, the cross-linguistic perspective adopted in this paper sheds light on longstanding debates regarding the nature of imperfectivity and its variation. Drawing both on macro-variation across language families and micro-variation within a language family, we have argued against views according to which IMPF carries no specific semantic information, and has a meaning determined either by other operators in the linguistic structure, or by means of purely pragmatic principles of a conversational type. We have also argued against pragmatic accounts based on competition and semantic underspecification, thus minimizing the role of pragmatics in favor of formal grammar from several points of view. (As noted in the text, however, we obviously do not claim that pragmatic inferences never play a role in the interpretation of imperfectives.) The cross-linguistic perspective has been crucial in the development of our arguments, since, as we have shown in various cases, a pragmatic account may appear appealing when considering a single language, but it may lose its appeal once we observe the systematic behavior of imperfectives across a number of languages.

Acknowledgements This version of the paper has benefitted from extremely helpful comments from three anonymous reviewers, whom we deeply thank. We also owe many thanks to Galia Dukova-Zheleva and Nikolay Slavkov for help with Bulgarian, Ewelina Frąckowiak for Polish and for obtaining Czech 
and Slovak materials, Viktor Kharlamov and Ulyana Savchenko for Russian, Milena Milojević Sheppard and Tatiana Marvin for Slovenian, and Bepkamrêk Kayapó, Ikrô Kayapó and the Djudjêkô community for Mẽbengokre. Earlier versions of portions of this paper were presented at WSCLA 16, Amherst, Massachusetts, in February 2011; Chronos 10, Birmingham, UK, in April 2011; MOSS 2, Moscow, Russia in April 2011; WCCFL 29, Tucson, Arizona, in April 2011; SULA 6, Manchester, UK, in May 2011; and the Workshop on Modality, Ottawa, Canada, in April 2012. We thank the audience of those conferences for useful comments, and in particular Olga Batiukova, Lena Karvovskaya, Yury Lander and Eugenia Romanova. Usual disclaimers apply. Research for this work was carried out with partial support from the Social Sciences and Humanities Research Council of Canada (Research Grant 410-2010-2040 to A. Arregui (PI), M.L. Rivero and A. Salanova (co-investigators), and Research Grant 410-2009-0828 to M.L. Rivero).

Open Access This article is distributed under the terms of the Creative Commons Attribution License which permits any use, distribution, and reproduction in any medium, provided the original author(s) and the source are credited.

\section{References}

Altshuler, Daniel Gordon. 2010. Temporal interpretation in narrative discourse and event internal reference. New Brunswick, NJ: Rutgers University dissertation.

Altshuler, Daniel Gordon. 2012. Aspectual meaning and discourse coherence: A look at the Russian imperfective. Journal of Semantics 29: 39-108.

Anand, Pranav, and Valentine Hacquard. 2009. The role of the imperfect in Romance counterfactuals. In Sinn und Bedeutung, eds. Martin Prinzhorn, Viola Schmitt, and Sarah Zobel, Vol. 14. 37-50. Vienna: University of Vienna.

Arregui, Ana. 2009. On similarity in counterfactuals. Linguistics and Philosophy 33: 245-278.

Arregui, Ana. 2010. Detaching if-clauses from should. Natural Language Semantics 18: 241-293.

Arregui, Ana, María Luisa Rivero, and Andrés Pablo Salanova. 2011. Imperfectivity: Capturing variation across languages. In Moscow Syntax and Semantics Workshop (MOSS) 2. (Submitted).

Austin, John. 1950. Truth. In Philosophical papers, 3rd edn., 117-133. Oxford: Oxford University Press. 1979.

Bary, Corien. 2009. Aspect in Ancient Greek. A semantic analysis of the aorist and imperfective. Nijmegen, Netherlands: Radboud University dissertation.

Bhatt, Rajesh. 2006. Covert modality in non-finite contexts. Berlin: Mouton de Gruyter.

Bhatt, Rajesh. 1999a. Actuality entailments of ability modals. In 17th West Coast Conference on Formal Linguistics, 74-87.

Bhatt, Rajesh. 1999b. Covert modality in non-finite contexts. Philadelphia, PA: University of Pennsylvania dissertation.

Bonami, Olivier. 2002. A syntax-semantics interface for tense and aspect in French. In HPSG conference 2001, 31-50. Stanford: CSLI Publications.

Boneh, Nora, and Edit Doron. 2008. Habituality and the habitual aspect. In Theoretical and crosslinguistic approaches to the semantics of aspect, ed. Susan Rothstein, 321-347. Amsterdam: John Benjamins.

Bonomi, Andrea. 1997. The progressive and the structure of events. Journal of Semantics 14: 173-205.

Borik, Olga. 2002. Aspect and reference time. Utrecht, Netherlands: University of Utrecht dissertation.

Borik, Olga. 2006. Aspect and reference time. New York: Oxford University Press.

Bybee, Joan L., Dale Perkins Revere, and William Pagliuca. 1994. The evolution of grammar. Tense, aspect, and modality in the languages of the world. Chicago/London: University of Chicago Press.

Cipria, Alicia, and Craige Roberts. 2000. Spanish imperfecto and pretérito: Truth conditions and aktionsart effects in a situation semantics. Natural Language Semantics 8: 297-347.

Cohen, Ariel. 1999. Generics, frequency adverbs, and probability. Linguistics and Philosophy 22: 221253.

Copley, Bridget. 2002. The semantics of the future. Cambridge, MA: MIT dissertation.

Cover, Rebecca Tamar. 2011. Modal aspects of Badiaranke aspect. Lingua 121: 1315-1343.

Dahl, Östen. 1985. Tense and aspect systems. London: Basil Blackwell.

de Swart, Henriëtte. 1998. Aspect shift and coercion. Natural Language \& Linguistic Theory 16: 347-385. 
de Swart, Henriëtte. 2011. Mismatches and coercion. In Semantics: An international handbook of natural language meaning, eds. Claudia Maienborn, Klaus von Heusinger, and Paul Portner. Berlin: De Gruyter (in press).

Deo, Ashwini. 2009. Unifying the imperfective and the progressive: Partitions as quantificational domains. Linguistics and Philosophy 32: 475-521.

Dickey, Stephen M. 2000. Parameters of Slavic aspect. A cognitive approach. Stanford: CSLI Publications.

Dočekal, Mojmír, and Ivona Kučerová. 2009. Aspectual presuppositions in Slavic and Romance. In Formal approaches to Slavic linguistics, Vol. 18, 125-139. Ann Arbor: Michigan Slavic Publications.

Dourado, Luciana. 2001. Aspectos morfossintáticos da língua Panará (Jê). Campinas: State University of Campinas dissertation.

Dowty, David R. 1979. Word meaning and Montague grammar. Dordrecht: Reidel.

Ferreira, Marcelo. 2005. Event quantification and plurality. Cambridge, MA: MIT dissertation.

Fici, Francesca. 2008. I costrutti riflessivi nelle lingue slave. Propensioni e disposizioni. Linguistica $e$ Filologia 26: 57-74.

Forsyth, John. 1970. A grammar of aspect. Cambridge: Cambridge University Press.

Frąckowiak, Ewelina. 2011. When epistemic modals need imperfective aspect. Generative Linguistics in Poland (GLiP) 7.

Giorgi, Alessandra, and Fabio Pianesi. 2001. Imperfect dreams. Probus 13: 31-68.

Giorgi, Alessandra, and Fabio Pianesi. 2004. On the speaker's and the subject's temporal representation. In The syntax of time, eds. Jacqueline Guéron and Jacqueline Lecarme, 259-298. Cambridge: MIT Press.

Grønn, Atle. 2003. The semantics and pragmatics of the Russian factual imperfective. Oslo: University of Oslo dissertation.

Grønn, Atle. 2008. Imperfectivity and complete events. In Interdependence of diachronic and synchronic analyses, eds. Folke Josephson and Ingmar Söhrman, 149-165. Amsterdam: John Benjamins.

Hacquard, Valentine. 2006. Aspects of modality. Cambridge, MA: MIT dissertation.

Heim, Irene. 1982. The semantics of definite and indefinite noun phrases. Amherst, MA: University of Massachusetts dissertation.

Heim, Irene, and Angelika Kratzer. 1998. Semantics in generative grammar. Oxford: Blackwell.

Hornstein, Norbert. 1999. Movement and control. Linguistic Inquiry 30: 69-96.

Ippolito, Michaela. 2004. Imperfect modality. In The syntax of time, eds. Jacqueline Guéron and Jacqueline Lecarme, 359-387. Cambridge: MIT Press.

Izvorski, Roumyana. 1997. The present perfect as an epistemic modal. Semantics and Linguistic Theory (SALT) 7.

Jayez, Jacques. 1999. Imperfectivity and progressivity: The French imparfait. Semantics and Linguistic Theory 9: 145-162.

Kagan, Olga. 2007. On the semantics of verbs of motion in Russian. Israel Association for Theoretical Linguistics (IATL) 23.

Kaufman, Terence. 1990. Language history in South America: What we know and how to know more. In Amazonian linguistics: Studies in lowland South American languages, ed. David Payne, 13-73. Austin: University of Texas Press.

Klein, Wolfgang. 1994. Time in language. New York: Routledge.

Kratzer, Angelika. 1989. An investigation of the lumps of thought. Linguistics and Philosophy 12: 607653.

Kratzer, Angelika. 1991. Modality. In Semantics: An international handbook of contemporary research, ed. Arnim von Stechow, 639-650. Berlin: Walter de Gruyter.

Kratzer, Angelika. 1998. More structural analogies between pronouns and tenses. Semantics and Linguistic Theory 8: 92-109.

Kratzer, Angelika. 2002. Facts: Particulars of information units? Linguistics and Philosophy 25: 655-670.

Kratzer, Angelika. 2011. Situations in natural language semantics. In Stanford encyclopedia of philosophy.

Labelle, Marie. 2003. Events, states and the French imparfait. In Romance linguistics: Theory and acquisition, eds. Ana M. Pérez-Leroux and Yves Roberge, 165-180. Amsterdam: John Benjamins.

Landman, Fred. 1989. Groups, II. Linguistics and Philosophy 12(6): 723-744.

Landman, Fred. 1992. The progressive. Natural Language Semantics 1: 1-32.

Lee, Eun Hee. 2008. Argument structure and event structure: The case of Korean imperfective constructions. Journal of East Asian Linguistics 17: 117-139. 
Lenci, Alessandro, and Pier Marco Bertinetto. 2000. Aspect, adverbs, and events: Habituality vs. perfectivity. In Speaking of events, eds. James Higginbotham, Fabio Pianesi, and Achille Varzi. Oxford: Oxford University Press.

Lewis, David. 1968. Counterpart theory and quantified modal logic. The Journal of Philosophy 65: 113126.

Lewis, David. 1986. On the plurality of worlds. London: Blackwell.

Menéndez-Benito, Paula. 2002. Aspect and adverbial quantification in Spanish. North East Linguistics Society 32: 365-382.

Menéndez-Benito, Paula. 2005. The grammar of choice. Amherst, MA: University of Massachusetts dissertation.

Moens, Marc, and Mark Steedman. 1988. Temporal ontology and temporal reference. Computational Linguistics 14: 15-28.

Padučeva, Elena. 1992. Toward the problem of translating grammatical meanings: The factual meaning of the imperfective aspect in Russian. Meta 37: 113-126.

Partee, Barbara. 1973. Some structural analogies between tenses and pronouns in English. The Journal of Philosophy 70: 601-609.

Popjes, Jack, and Jo Popjes. 1986. Canela-Krahô. In Handbook of Amazonian languages, eds. Desmond C. Derbyshire and Geoffrey K. Pullum, Vol. 1, 128-199. Berlin: Mouton de Gruyter.

Portner, Paul. 1998. The progressive in modal semantics. Language 74: 760-786.

Reis Silva, Maria Amélia, and Andrés Pablo Salanova. 2000. Verbo y ergatividad escindida en Mẽbengokre. In Indigenous languages of lowland South America, eds. Hein van der Voort and Simon van de Kerke. Leiden: Research School of Asian, African, and Amerindian Studies (CNWS), Leiden University.

Reyes, Graciela. 1990. Valores estilísticos del imperfecto. Revista de Filología Española 70: 45-70.

Riegel, Martin, Jean-Christophe Pellat, and René Rioul. 1994/1998. Grammaire méthodique du français. Paris: PUF.

Rivero, María Luisa. 2005. Topics in Bulgarian morphology and syntax: A minimalist perspective. Lingua 115: 1083-1128.

Rivero, María Luisa. 2009. Intensionality, high applicatives, and aspect: Involuntary state constructions in Bulgarian and Slovenian. Natural Language \& Linguistic Theory 27: 151-196.

Rivero, María Luisa, and Ana Arregui. 2010. Variation in Slavic imperfectives. In 2010 annual conference of the Canadian Linguistic Association. http://www.chass.utoronto.ca/ cla-acl/actes2010/ actes2010.html.

Rivero, María Luisa, and Ana Arregui. 2012. Building involuntary states in Slavic. In Telicity, change, and state: A cross-categorial view of event structure, eds. Violeta Demonte and Louise McNally, 300-332. New York: Oxford University Press.

Rivero, María Luisa, and Milena M. Sheppard. 2008. Revisiting Involuntary State Constructions in Slovenian. In Studies in Formal Slavic Linguistics, eds. Franc Maruşič and Rok Z̧aucer, 273-290. Frankfurt: Peter Lang.

Rivero, María Luisa, Ana Arregui, and Ewelina Frąckowiak. 2010. Variation in circumstantial modality: Polish vs. St'át'imcets. Linguistic Inquiry 41: 704-714.

Rodríguez, Joshua P. 2004. Interpreting the Spanish imperfecto: Issues of aspect, modality, tense, and sequence of tense. Columbus, $\mathrm{OH}$ : The Ohio State University dissertation.

Rullmann, Hotze, Lisa Matthewson, and Henry Davis. 2008. Modals as distributive indefinites. Natural Language Semantics 16: 317-357.

Salanova, Andrés Pablo. 2007. Nominalizations and aspect. Cambridge, MA: MIT dissertation.

Salanova, Andrés Pablo. 2008. Uma análise unificada das construções ergativas do Mẽbengokre. Amérindia 32: 109-134.

Salanova, Andrés Pablo. 2011. Relative clauses in Mẽbengokre. In Subordination in South American languages, eds. Pieter Muysken, Rik van Gijn, and Katharina Haude. Amsterdam: John Benjamins.

Salanova, Andrés Pablo. 2014. Reduplication and number in Mẽbengokre. In Reduplication in indigenous languages of South America, eds. Gale Goodwin Gómez and Hein van der Voort. Leiden: Brill.

Salanova, Andrés, and Maria Amélia Reis Silva. 2011. Le Mẽbengokre. In Dictionnaire des langues, eds. Emilio Bonvini, Joëlle Busuttil, and Alain Peyraube. Paris: PUF.

Salanova, AndrésPablo, María Luisa Rivero, and Ana Arregui. 2012. Imperfectives in Mẽbengokre. In Proceedings of the Sixth Conference on the Semantics of Under-represented Languages in the Americas (SULA 6) and SULA-Bar, ed. Elizabeth Bogal-Allbrittenm. Amhers: GLSA.

Scatton, Ernest. 1983. A reference grammar of Modern Bulgarian. Columbus: Slavica. 
Smith, Carlota S. 1991. The parameter of aspect. Dordrecht: Kluwer.

Smith, Carlota S. 1997. The parameter of aspect, 2nd edn. Dordrecht: Kluwer.

Togeby, Knut. 1982. Grammaire française. Vol. 2. Copenhague: Akademisk Forlag.

Urban, Greg. 1985. Ergativity and accusativity in Shokleng (Gê). International Journal of American Linguistics 51: 164-187.

Wiesemann, Ursula. 1972. Die phonologische und grammatische Struktur der Kaingang-Sprache. The Hague: Mouton.

Wiesemann, Ursula. 1986. Aspect and mood as a nine-cell matrix. In Language in a global perspective, ed. Benjamin F. Elson. Dallas: SIL.

Zucchi, Alessandro. 1999. Incomplete events, intensionality, and imperfective aspect. Natural Language Semantics 7: 179-215. 